\title{
ALGUNAS PRECISIONES EN TORNO AL ALCANCE DE LAS CONSECUENCIAS ECONÓMICAS, SOCIALES Y DEMOGRÁFICAS DEL CULTIVO DE LA PATATA EN LA GALICIA DE FINALES DEL ANTIGUO RÉGIMEN ${ }^{1}$
}

\author{
Hortensio Sobrado CORREA \\ Universidad de Santiago de Compostela
}

\begin{abstract}
RESUMEN. Entre los objetivos de este trabajo está hacer algunas precisiones acerca de la periodización de la introducción y progresión del cultivo de la patata en la Galicia de la Edad Moderna, prestando atención a los factores desencadenantes de su expansión, así como al papel jugado en la difusión de la nueva planta por la iniciativa campesina frente al fomento institucional. Igualmente, se pretende precisar el alcance de las consecuencias económicas, sociales y demográficas que desde finales del siglo XVIII y a lo largo de la primera mitad del XIX tuvo la implantación de las patatas en el sistema agrario gallego, a fin de aquilatar el verdadero protagonismo que dicho tubérculo de origen americano adquirió en territorio gallego.

Palabras clave: cultivos americanos, patata, Antiguo Régimen, Galicia, intensificación agraria, crecimiento demográfico.
\end{abstract}

ABSTRACT. Among the objectives of this work is to make some precisions about the periodization of the introduction and progression of the cultivation of the potato in the Galicia of the Modern Age, paying attention to the factors that triggered its expansion, as well as the role played in the diffusion of the new plant by the peasant initiative in the face of institutional development. Likewise, it is intended to specify the extent of the economic, social and demographic consequences that since the late eighteenth century and throughout the first half of the nineteenth

Recibido: 8-10-2018 • Aceptado: 14-11-2018 • hortensio.sobrado@usc.es

Trabajo realizado en el marco del Proyecto de Investigación HAR2014-52667-R, financiado por el Ministerio de Economía y Competitividad. Agradezco a los evaluadores anónimos sus comentarios y consideraciones. 
century had the introduction of potatoes in the Galician agrarian system, in order to assess the true role that said tubercle of American origin acquired in Galician territory.

Keywords: American crops, potatoes, Ancien Regime, Galicia, agrarian intensification, population growth.

«No dexen de repetir siempre que puedan la excelencia de tan preciosa raíz que nos ha dado la América, y que por ella sola se pueden dar por bien empleadas todas las fatigas de sus conquistadores».

Cura de Linares (1797)

EN EL TRANSCURSO de la Edad Moderna, en el contexto de una auténtica transferencia intercultural entre continentes (Yun, 2014; Galli, 2016), la implantación y progresiva generalización de nuevas plantas de origen americano, como el maíz y las patatas, supuso en Galicia una cascada de profundas transformaciones en el sistema agrario, que habrían de cobrar un destacado protagonismo en los procesos de intensificación agropecuaria y de crecimiento de la población experimentados en tierras gallegas a lo largo de los siglos XVII-XIX (Pérez García, 1981, 1992 y 2006; Rodríguez Ferreiro, 1995 y 2003; Saavedra, 1992 y 1999).

Conscientes de la relevancia de estas transformaciones para el conocimiento de las dinámicas evolutivas, tanto agraria como demográfica, planteamos como principal objetivo de este trabajo hacer algunas precisiones, sobre el verdadero alcance de la difusión de la patata, así como acerca de las consecuencias económicas, sociales y demográficas que dicho cultivo tuvo en Galicia, fundamentalmente a partir del último tercio del XVIII y en el transcurso de la primera mitad del XIX. Para ello hemos recurrido al entrecruzamiento de fuentes de diversa naturaleza, tanto de carácter eclesiástico (archivos parroquiales, libros de fábrica, valoraciones de curatos, libros de cuentas de prioratos y monasterios), notarial (inventarios post-mortem, compraventas, contratos agrarios, etc.), como fiscal - Catastro de Ensenada (1752), Comprobaciones (1761), Frutos Civiles (1787-1845)—, o judicial (pleitos civiles ante jueces locales o provisores diocesanos, y procesos litigados ante la Real Audiencia de Galicia).

\section{Periodización de la introducción y progresión del cultivo de la patata}

La difusión de las patatas en España se inicia relativamente tarde con respecto a otros países europeos (Piqueras, 1992, p. 88), pues a mediados del XVIII sólo eran cultivadas de manera más o menos regular en las Canarias, en el corazón de la Mancha, 
y en algunas áreas de la Galicia cantábrica e interior o de Asturias occidental, aunque también se habían introducido en el noroeste de Murcia y valles septentrionales extremeños (Lobo, 2008, p. 232; Anes, 1985, p. 513; Faya, 2007, p. 1033; Sánchez Romero, 1990, p. 264; Melón, 1989, p. 97). En la mayor parte del país las patatas, aunque se conocían con anterioridad, no se generalizarán hasta el XIX (Rodríguez Galdo, 1991; García Ruíz, 1991), como ocurre en tierras leonesas, en el País Vasco, Cataluña o Valencia, entre otras (Rubio, 1987, p. 269; Pérez Álvarez, 1996, p. 145; García García, 2013, p. 373; Fernández de Pinedo, 1974; Riera, 2007; Bilbao, 1984, p. 166; Congost, 1989, p. 182; Durán, 1997; Fábrega, 2017; Ardit, 2007, p. 59; Brines, 1996, p. 64).

Las primeras noticias sobre su cultivo en Galicia tienen lugar en el último tercio del XVI, cuando el Arzobispo Francisco Blanco (1574-1581) hizo plantar el tubérculo americano en las huertas del monasterio de Herbón (Padrón) (Hoyo, 2016, p. 187v). La inexistencia de testimonios durante el XVII hace pensar que durante dicho período su explotación se limitaría a ensayos puntuales (Bouhier, 2001, p. 790). No volvemos a tener evidencias documentales de la siembra de patatas en Galicia hasta 1736, cuando el párroco de Santiago de Bravos (Mondoñedo) se querella de sus feligreses, ya que «...se yntroduzco aora de próximo una especie de fruta que llaman castañas mariñas o criadillas de la tierra...» (Saavedra, 1985, p. 181). De igual modo, según un pleito sobre tributación diezmal de Río Freixo (Ourense), el plantío de patatas ya se había introducido hacia $1740^{2}$. En 1750 el inventario post-mortem de Antonia Rodríguez, de Santa Marina de Rioseco, en dicha comarca orensana de La Limia, incluye «cosa de unas tres tegas de castañas que llaman da India» ${ }^{3}$. Precisamente, el Catastro de Ensenada (1752) sólo registra el cultivo de patatas en 4 parroquias de Ourense: Coedo (Allariz), Orille, Pitelos y Portela (Verea), diferenciando claramente las «castañas que producen los sotos», de las «castañas que llaman yndias que producen algunas tierras labradías $»^{4}$. Información corroborada casi una década después por las Comprobaciones del Catastro (1761) . Por tanto, las primeras evidencias documentales constatarían su cultivo antes de 1750 en las antiguas provincias de Mondoñedo y Ourense.

El Censo de la Riqueza Territorial e Industrial de España de 1799 coloca a Galicia como una de las principales áreas productoras de batatas de la Península (Piqueras, 1992, p. 81). Sin embargo, dicha tendencia regional escondía grandes diversidades comarcales. Las Relaciones de Frutos Civiles (1788-1791) confirman la importancia

Archivo del Reino de Galicia (en adelante ARG), Real Audiencia, Vecinos, 26315/5.

Archivo Histórico Provincial de Ourense (en adelante AHPO), Protocolos, 1444/1, fol. 79.

Archivo General de Simancas (en adelante AGS), Catastro de Ensenada, Respuestas Generales (CE-RG), 225-536, 226-009, 225-496, 225-529.

AGS, Dirección General de Rentas, $1^{a}$. Remesa (DGR, $1^{a}$. R.), 1091/2, 1116/1, 1121/15, 1122/10, $1132 / 2$. 
Mapa 1. Las siete provincias del Antiguo Reino de Galicia

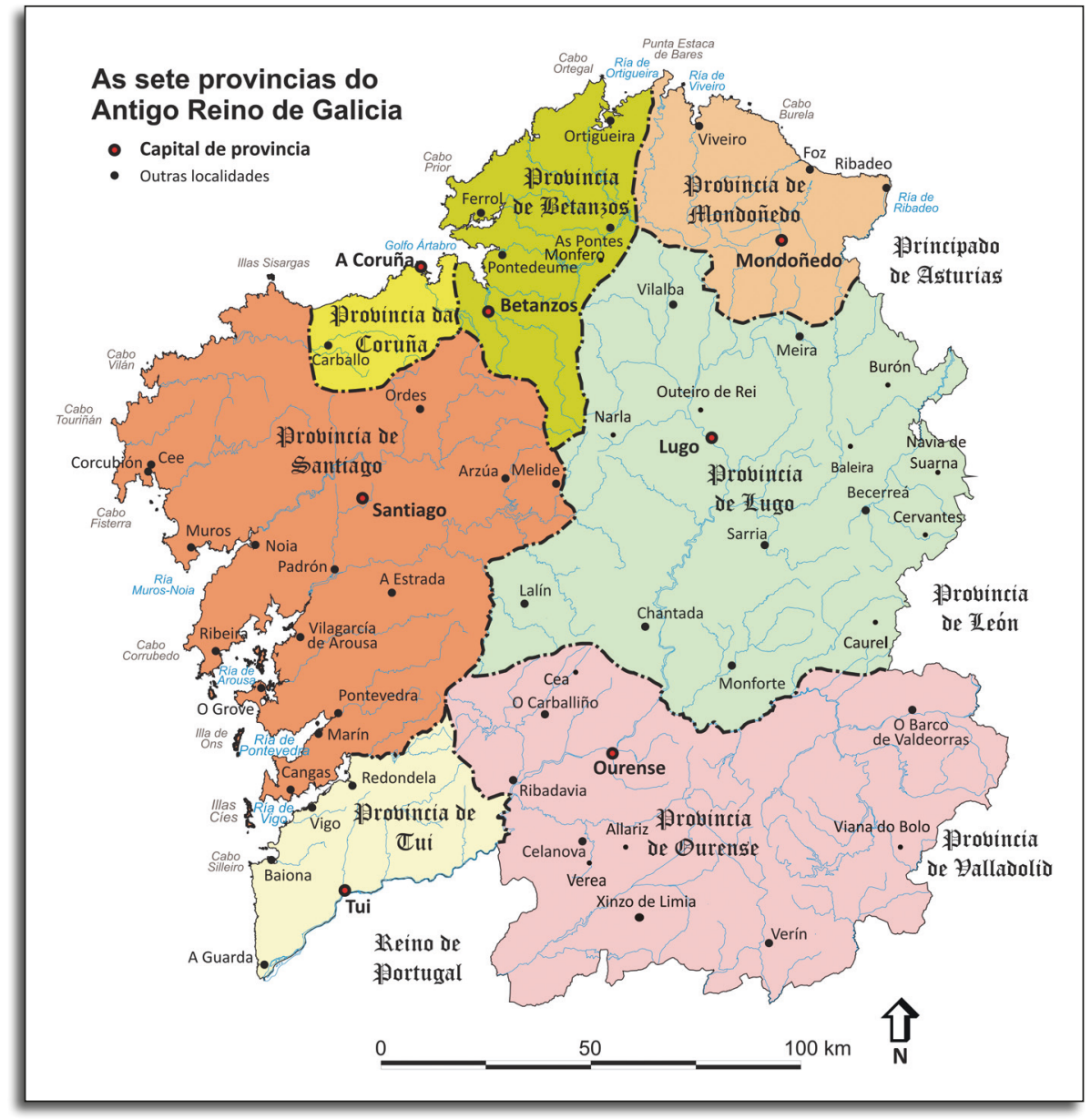

Elaborado por Juan López Bedoya

que van adquiriendo las patatas en las antiguas provincias de Mondoñedo y Lugo. En tierras mindonienses mientras que en el litoral y valles apenas suponen el $5 \%$ de la cosecha, en zonas de montaña (Muras-Bretoña) podían alcanzar el 40-50 \% del total cosechado, por lo que proliferan mejor en las tierras altas centeneras, allí donde no tienen que desplazar al maíz (Saavedra, 1985, p. 184). En el área oriental lucense (Burón-Navia de Suarna), según los Frutos Civiles el tubérculo representa el 30-35 \%, y en la transición a la montaña (Baleira), en torno al 20-25\% (Tabla 1), con lo que, a medida que nos alejamos de la montaña hacia a la meseta, en donde ha de superar las rígidas rotaciones vigentes en las agras, se observa una menor progresión. 
Tabla 1. Cosechas según Relaciones de Frutos Civiles, 1788-1791 Partidos de Burón, Navia de Suarna y Baleira (Lugo, en kilogramos)

\begin{tabular}{|c|c|c|c|c|c|c|}
\hline Partido de Burón (1788) & Centeno & Trigo & Maíz & Avenas & Patatas & $\%$ Patatas \\
\hline San Martiño de Suarna & 170.720 & 880 & 8.800 & 2.640 & 109.560 & 37,4 \\
\hline San Miguel de la Bastida & 142.120 & - & 220 & 4.400 & 135.080 & 47,9 \\
\hline San Cibrao de Monteseiro & 55.880 & 440 & 3.432 & 1.760 & 6.160 & 9,1 \\
\hline Lamas de Suarna & 207.680 & 1.540 & 2.200 & - & 108.240 & 33,8 \\
\hline Trobo y S. Martiño & 172.480 & 440 & 4.840 & 16.720 & 63.624 & 24,6 \\
\hline Total (kg). y \% & 748.880 & 3.300 & 19.492 & 25.520 & 422.664 & 34,6 \\
\hline \multicolumn{7}{|l|}{ Partido Navia de Suarna (1788) } \\
\hline Santiago de Moya & 22.000 & - & - & - & 9.900 & 31,0 \\
\hline \multicolumn{7}{|l|}{ Partido de Baleira (1791) } \\
\hline Santa María de Librán & 14.300 & 220 & - & 2.640 & 4.400 & 20,4 \\
\hline Santigo de Martín & 15.400 & - & 220 & 3.520 & 880 & 4,3 \\
\hline San Miguel de Braña & 11.880 & 220 & - & - & 2.090 & 14,7 \\
\hline Santa María de Fonteo & 11.000 & 330 & - & - & 2.200 & 16,2 \\
\hline Santa Magdalena de Retizós & 15.400 & 1.100 & - & - & 4.400 & 21,0 \\
\hline Santiago de Cubilledo & 2.200 & - & - & 4.400 & 11.000 & 62,5 \\
\hline Total $(\mathrm{kg})$ y $\%$ & 70.180 & 1.870 & 220 & 10.560 & 24.970 & 23,1 \\
\hline TOTAL & 841.060 & 5.170 & 19.712 & 33.440 & 457.534 & 33,7 \\
\hline
\end{tabular}

Fuente: Archivo Histórico Provincial de Lugo (en adelante AHPL), Hacienda, Frutos Civiles, Legs. 15282; 15325 y 878 .

En Ourense la patata tarda más en introducirse en el sistema agrario. En las Relaciones de Frutos Civiles (1787) sólo se menciona en los municipios de Muiños, Maceda, Manzaneda, Laza, Xunqueira de Espadañedo y Riós (en el sector suroriental), en el que únicamente la nueva planta alcanza un tercio del cereal cosechado (Rodríguez Fernández, 2006, p. 119).

Las valoraciones de curatos de principios del XIX reflejan la importante progresión de las patatas en el interior de Mondoñedo, pues entre 1794-1804 en San Pedro de Labrada la producción se sextuplica, llegando casi al $50 \%$ de la de cereales (Saavedra, 1994, p. 151). Igualmente, en Muras el Libro de Fábrica constata que el tubérculo se impone como principal cultivo de primavera, alcanzando en 1805-1811 el 63,2 \% de la cosecha (Saavedra, 1985, p. 186). En el área oriental de Lugo, según las relaciones de frutos diezmales que perciben los párrocos en sus curatos (1805-1825), en los arciprestazgos de Neira de Jusá (Baralla) y Cervantes-Caurel, la patata supone casi el $30 \%$ de los cereales, y la mitad del centeno (Tabla 2).

Por lo que respecta a los monasterios gallegos, el tubérculo americano apenas repercutía en las rentas monásticas. Los cenobios que cobraban diezmos de patatas no solían percibirlos en especie, sino en dinero o en otro cereal como el centeno. Así, Xunqueira de Espadañedo (Ourense) acordó con los campesinos que le pagasen en centeno en proporción a la superficie sembrada de patatas (Saavedra, 2010, p. 105). 
Tabla 2. Relaciones de frutos diezmales, 1805-1825 (en kilogramos)

\begin{tabular}{|l|c|c|c|c|c|c|c|c|}
\hline Neira de Jusá, 1805 & Centeno & Trigo & Cebada & Avena & Maíz & Mijo & Patatas & $\%$ Patatas \\
\hline San Juan de Lejo & 2.200 & 176 & 308 & - & - & - & 308 & 10,2 \\
\hline Santa María de Pol & 1.056 & 176 & 132 & - & 44 & - & 1.760 & 55,5 \\
\hline San Jorge de Val & 2.992 & 220 & 264 & 264 & 88 & - & 1.848 & 32,5 \\
\hline San Mamed de Traspena & 352 & 16,28 & 176 & - & 44 & - & 220 & 27,2 \\
\hline San Pedro de Sigerey & 880 & 264 & 264 & 44 & 22 & - & 440 & 22,9 \\
\hline Santiago de Covas & 968 & 88 & 132 & - & 220 & - & 264 & 15,7 \\
\hline San Tomé de Lebrujo & 396 & 33 & 66 & - & 176 & - & 198 & 22,7 \\
\hline Total (kg) y \% & 8.844 & 973,2 & 1.342 & 308 & 594 & - & 5.038 & 29,4 \\
\hline Caurel, 1805 & & & & & & & & \\
\hline Santa María de Folgoso & 2.200 & - & - & - & 44 & - & 880 & 28,1 \\
\hline Santa María de Jestoso & 1.760 & 5,3 & - & - & 11 & - & 264 & 12,9 \\
\hline Secada de Caurel & 2.200 & 66 & 5,3 & - & - & 176 & 528 & 17,7 \\
\hline Total (kg) y \% & 5.720 & 71,3 & 5,3 & - & 385 & 176 & 2.112 & 24,9 \\
\hline Cervantes y Caurel, 1825 & & & & & & & & \\
\hline San Tomé de Cancelada & 4.180 & 176 & 110 & - & - & - & 880 & 16,4 \\
\hline San Vicente de Villamor & 2.200 & - & - & - & 330 & & 880 & 25,8 \\
\hline Total (kg) y \% & 6.380 & 176 & 110 & - & 330 & - & 1.760 & 20,1 \\
\hline TOTAL & 20.944 & $1.220,5$ & $1.457,3$ & 308 & 1.309 & 176 & 8.910 & 25,9 \\
\hline
\end{tabular}

Fuente: Archivo Diocesano de Lugo (ADL), Pleitos civiles, Mazos 6-7,15.

\section{Gráfico 1. Porcentaje del diezmo de patatas en el total cobrado Priorato de Santa María de Moreira, 1826-1834}

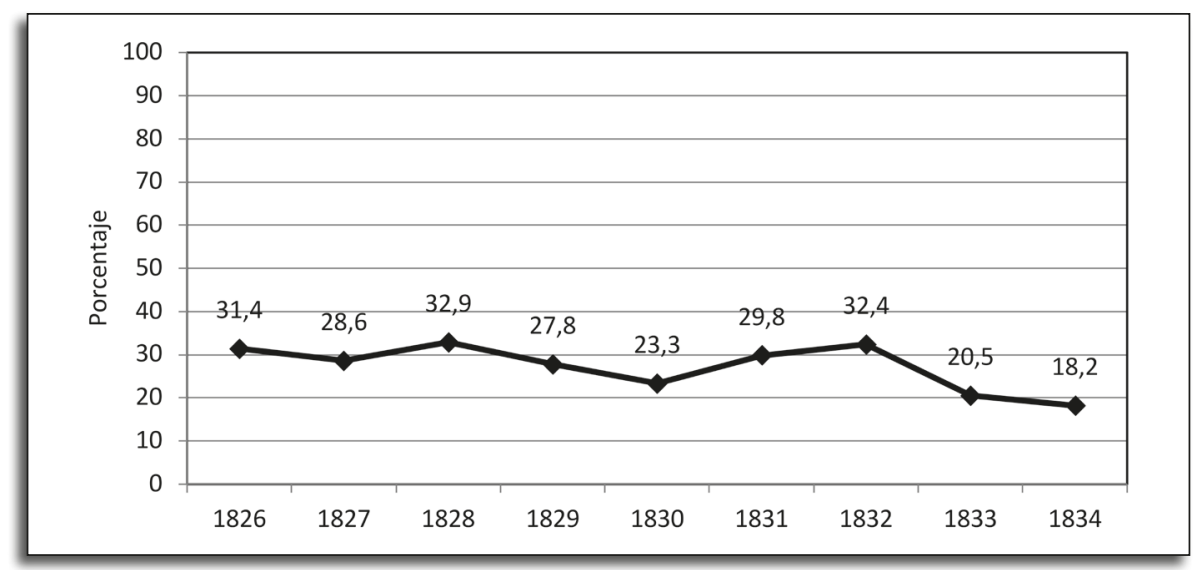

Fuente: AHN, Clero, Lib. 6229. 
El monasterio de Meira cobraba los diezmos en patatas en el priorato de Moreira (Lugo). Su libro de cuentas entre 1826-1834, muestra como éstas se aproximan a un tercio del total de ingresos diezmales del priorato (Gráfico 1) ${ }^{6}$. Por el contrario, en la Galicia occidental, el monasterio de Monfero cobraba desde 1805 diezmo de patatas en dinero. Según el libro de panera hasta 1816 el porcentaje de ingresos diezmales del tubérculo apenas supone el $5 \%$ para, entre 1817-1820, llegar a alcanzar el $17 \%$ (Gráfico 2) ${ }^{7}$.

\section{Gráfico 2. Porcentaje del diezmo de patatas en el total cobrado Monasterio de Monfero, 1805-1820}

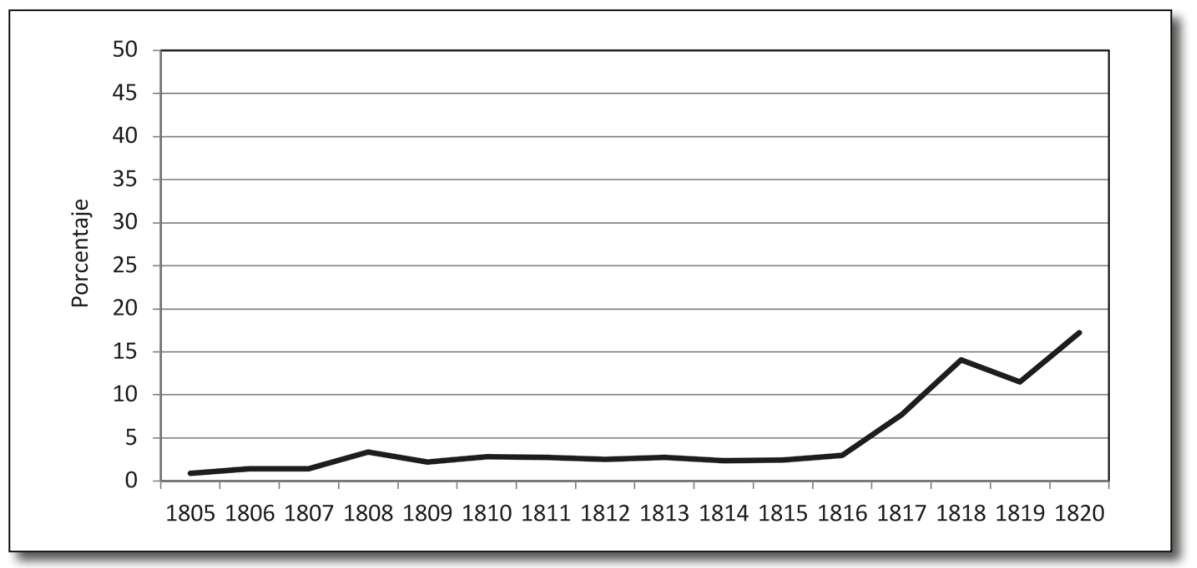

Fuente: ARG, Monasterios, 45212/282.

Por otra parte, los inventarios post-mortem también ofrecen una aproximación acerca de la progresión de las patatas en Galicia. En la antigua provincia de Mondoñedo, en la segunda mitad del XVIII, se observa una clara diferenciación entre las áreas del litoral, en las que las patatas apenas suponen el $1 \%$ de la cosecha inventariada, y zonas más interiores como el curso medio del Eo, en las que representan algo más del $30 \%$ del total cosechado (Saavedra, 1985, p. 186).

A través de una muestra de algo más de un millar de inventarios del centro y montañas de Lugo (Cervantes), así como de las comarcas orensanas de Xinzo de Limia y Verín, podemos examinar la evolución de las existencias de patatas en las despensas campesinas entre 1750-1850, en estas zonas de la Galicia oriental (Tabla 3). Desde 1780

Archivo Histórico Nacional (en adelante AHN), Clero, Lib. 6229.

ARG, Monasterios, 45212/282. 
Tabla 3. Evolución de las existencias de patatas según los inventarios post-mortem, 1750-1850. Ourense (Xinzo y Verín) y Lugo (Interior lucense y Cervantes)

\begin{tabular}{|c|c|c|c|c|c|}
\hline Xinzo Limia & Inventarios & Con patatas & $\%$ & Fgas./Explotación & $\%$ sobre cosecha \\
\hline $1750-1759$ & 6 & 1 & 16,6 & 0,6 & 0,2 \\
\hline 1760-1769 & 6 & - & - & - & - \\
\hline 1770-1779 & 12 & - & - & - & - \\
\hline 1780-1789 & 19 & - & - & - & - \\
\hline 1790-1799 & 54 & 2 & 3,7 & 1,0 & 1,4 \\
\hline 1800-1809 & 22 & 1 & 4,5 & 1,0 & 1,2 \\
\hline 1810-1819 & 24 & 5 & 20,8 & 4,8 & 35,4 \\
\hline 1820-1829 & 66 & 10 & 15,1 & 6,2 & 14,7 \\
\hline 1830-1839 & 56 & 7 & 12,5 & 10,0 & 22,4 \\
\hline 1840-1849 & 24 & 6 & 25,0 & 6,3 & 50,8 \\
\hline \multicolumn{6}{|l|}{ Verín } \\
\hline $1750-1759$ & 31 & - & - & - & - \\
\hline 1760-1769 & 40 & - & - & - & - \\
\hline $1770-1779$ & 2 & - & - & - & - \\
\hline $1780-1789$ & 3 & - & - & - & - \\
\hline 1790-1799 & 21 & 2 & 9,5 & 5,0 & 10,4 \\
\hline 1800-1809 & 7 & - & - & - & - \\
\hline 1810-1819 & 23 & 7 & 30,4 & 7,0 & 50,3 \\
\hline 1820-1829 & 52 & 15 & 28,8 & 8,8 & 70,2 \\
\hline 1830-1839 & 24 & 7 & 28,2 & 6,5 & 34,4 \\
\hline 1840-1849 & 51 & 13 & 25,5 & 8,5 & 72,4 \\
\hline $1850-1859$ & 26 & 7 & 25,9 & 6,1 & 72,2 \\
\hline \multicolumn{6}{|l|}{ Interior Lugo } \\
\hline $1750-1759$ & 32 & - & - & - & - \\
\hline 1760-1769 & 15 & - & - & - & - \\
\hline 1770-1779 & 6 & - & - & - & - \\
\hline 1780-1789 & 54 & 4 & 7,4 & 2,6 & 18,4 \\
\hline 1790-1799 & 16 & 5 & 31,2 & 3,8 & 59,0 \\
\hline 1800-1809 & 40 & 13 & 32,5 & 8,1 & 57,5 \\
\hline 1810-1819 & 24 & 5 & 29,8 & 7,4 & 35,5 \\
\hline 1820-1829 & 16 & 6 & 37,5 & 10,6 & 38,3 \\
\hline 1830-1839 & 12 & 6 & 54,5 & 10,8 & 52,3 \\
\hline \multicolumn{6}{|l|}{ Cervantes } \\
\hline $1750-1759$ & 23 & - & - & - & \\
\hline 1760-1769 & 23 & - & - & - & \\
\hline 1770-1779 & 15 & - & - & - & \\
\hline 1780-1789 & 40 & - & - & - & \\
\hline 1790-1799 & 35 & 3 & 8,6 & 3,2 & 8,7 \\
\hline 1800-1809 & 25 & 1 & 4,0 & 6,0 & 24,4 \\
\hline 1810-1819 & 31 & 1 & 3,2 & 20,0 & 12,8 \\
\hline $1820-1829$ & 14 & 7 & 50,0 & 8,0 & 38,8 \\
\hline 1830-1839 & 33 & 18 & 54,5 & 12,0 & 33,8 \\
\hline 1840-1849 & 32 & 15 & 46,8 & 18,0 & 75,4 \\
\hline Total & 1.054 & 167 & 15,8 & & \\
\hline
\end{tabular}

Fuente: AHPO, Protocolos, 1444-1450, 1510-1511, 1520-1531, 1554-1555, 1565, 1573-1576, 1618-1620, 2559-2560, 2564-2565, 2584, 2611, 2671-2673. AHPL, Protocolos, 350, 502, 506-509, 599-553, 593-597, 601-603, 623-625, 690-693, 706-708, 716-718, 802-808, 2458, 2475, 2501, 6412-6418, 6422-6425, 6589-6590, 6593-6594, 6625-6626, 6691-6692, 6719. 
se constata una creciente progresión tanto de los inventarios con presencia de patatas, como de las existencias por explotación, y de su proporción sobre el total cosechado.

\section{Gráfico 3. Progresión de los inventarios post-mortem con existencias de patatas, 1780-1850. Galicia oriental}

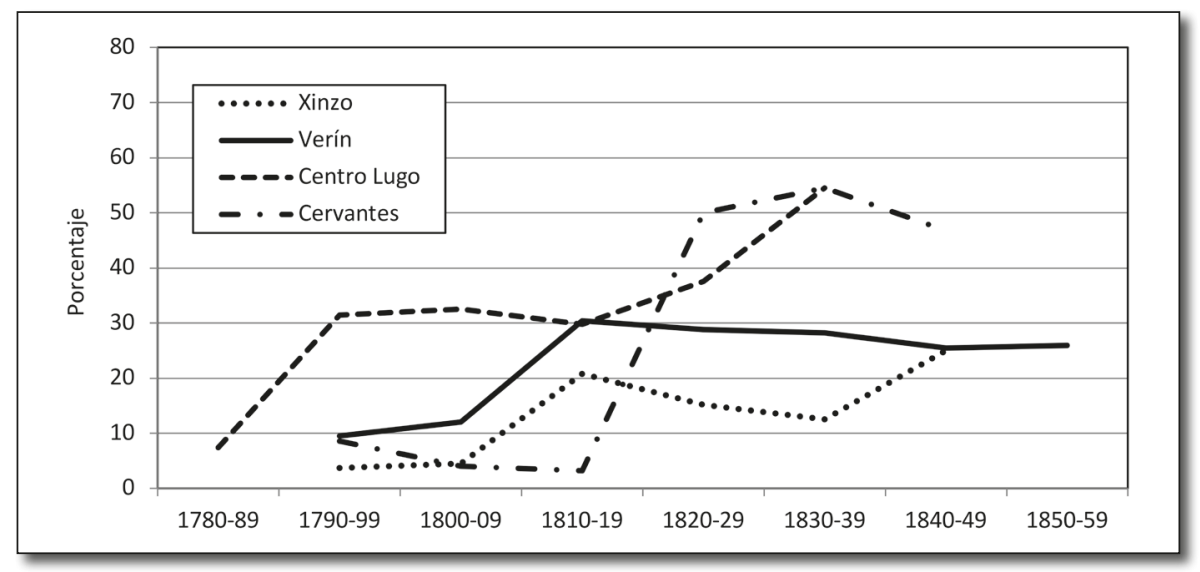

Fuente: Elaboración propia. Documentación citada Tabla 3.

En el centro de Lugo hay una presencia más temprana de las patatas en los inventarios, del orden del $30 \%$ en 1790-1799, mientras que en las montañas de Cervantes, o en tierras orensanas (Verín-Xinzo) apenas llegan a alcanzar el $10 \%$. Será a partir de las dos primeras décadas del XIX, cuando las patatas empiecen a tener presencia en los inventarios orensanos, en torno al 20-30\%, y desde 1820 en la mitad de los de Cervantes (Gráfico 3).

Según los inventarios del interior lucense, entre 1780-1789 las patatas suponían alrededor del $18 \%$ de las existencias de productos agrarios en las despensas campesinas. En la primera mitad del XIX dicho porcentaje ya había ascendido al $48 \%$ y en las montañas de Cervantes al $43 \%$, llegando a superar el $75 \%$ en 1850 . A finales del XVIII los inventarios aún reflejan una tímida expansión de las patatas en tierras de Ourense - Verín (10 \%) y Xinzo (1,5\%) de las reservas - . En la primera mitad del XIX su cultivo va progresando en las áreas centeneras del sureste, de modo que en Verín ya alcanzaba casi el $70 \%$ de las provisiones, y en Viana do Bolo el $35 \%$ (Quiroga Barro, 1988); mientras que en zonas más occidentales su implantación va más lenta, por lo que en Xinzo aún representaba el $20 \%$, y en la comarca de Celanova la patata apenas progresa en los campos ante el claro dominio del maíz, significando un escaso $8 \%$ de las provisiones campesinas en 1830-1850 (Rodríguez Fernández, 2006, p. 117). 


\section{Gráfico 4. Progresión de las patatas sobre el total cosechado según los inventarios post-mortem, 1780-1850. Galicia oriental}

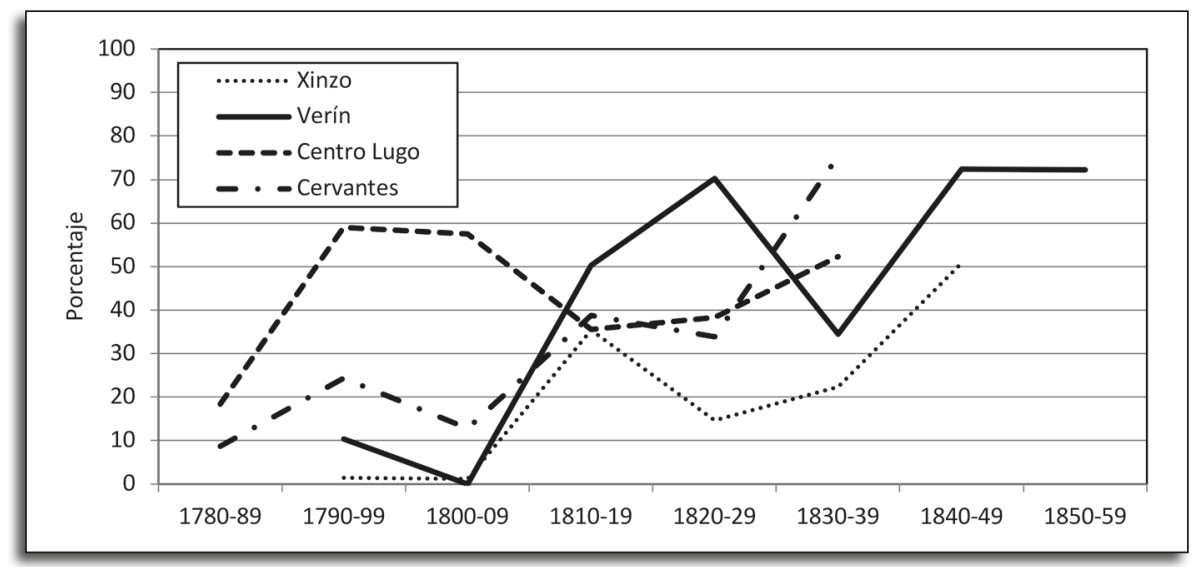

Fuente: Elaboración propia. Documentación citada Tabla 3.

Frente a la progresiva implantación de las patatas desde 1780 en la Galicia oriental, en la occidental resulta mucho menos intensa; así, el promedio anual cosechado en la antigua provincia de Santiago en 1789 apenas suponía el 0,4\% del total, muy por detrás del alcanzado por cereales como el maíz (64,2\%), centeno (24,2\%) o trigo $(11,1 \%)^{8}$. Entre los productos agrarios presentes en las explotaciones campesinas del partido judicial de Arzúa, según los inventarios (1819-1845), las patatas apenas constituyen un 7 \% (Presedo, 1997, p. 260 y 2009, p. 137).

Los pleitos por demanda diezmal ante la Real Audiencia de Galicia permiten precisar el momento en que el tubérculo se expande por territorio gallego, así como su distribución geográfica (Mapa 2). A través de una muestra de más de medio centenar de litigios hemos constatado la proliferación de demandas de los perceptores de diezmos exigiendo que los campesinos contribuyan por las patatas, a partir del último tercio del XVIII, con su punto álgido entre 1790-1810. En 1760-1819 las querellas se concentran en la Galicia oriental, tanto en las montañas septentrionales, como en tierras de Lugo y Ourense, zonas en las que las patatas ya no constituían una producción marginal, alcanzando cierta difusión. Hasta 1820 los litigios no afloran en la Galicia occidental.

Los datos de los Diccionarios de Sebastián Miñano (1826-1829) y de Pascual Madoz (1845-1850) permiten una lectura cartográfica de la distribución del cultivo de patatas en Galicia en ambos momentos de la primera mitad del XIX (Mapa 3) (Rodrí-

Archivo Municipal de Santiago (en adelante AMS), Consistorios, 1792, 1er. sem., fol. 49. 


\section{Mapa 2. Distribución geográfica de los pleitos por demanda diezmal de las patatas ante la Real Audiencia de Galicia, 1760-1840}

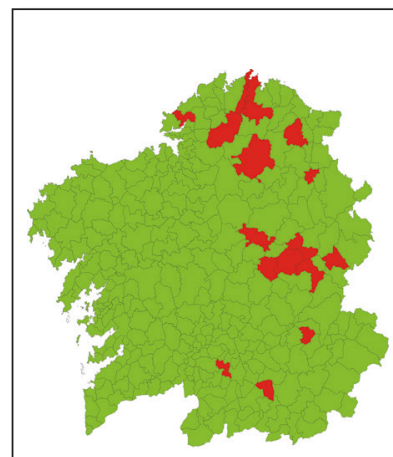

(1760-1799)

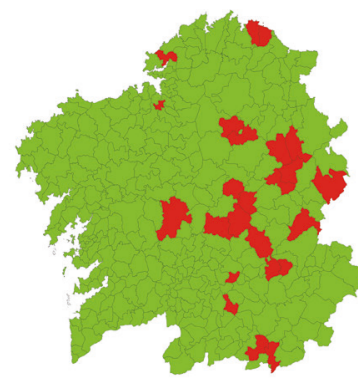

(1800-1819)

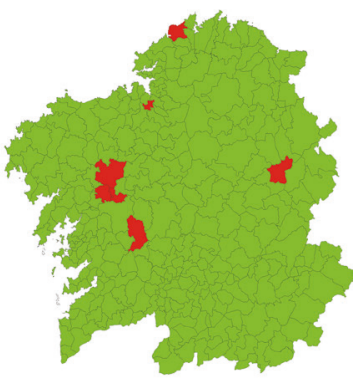

(1820-1840)

Fuente: Elaboración propia. ARG, Real Audiencia.

guez Galdo y Dopico, 1980, p. 27; Bouhier, 2001, p. 744). El Diccionario GeográficoEstadístico de Miñano constata cómo en las zonas más septentrionales y orientales de Galicia el 80-100 \% de las parroquias cultivaban patatas. En las áreas occidental orensana y meridional del valle del Miño, en las que había dificultades para implantarse, al ser zonas de maíz y viñedo, se observa un importante retraso en la expansión del tubérculo americano, que aparece en el 20-40 \% de las parroquias. Por último, en el litoral sudoccidental los obstáculos para desplazar al maíz de las rotaciones hacen que en menos del $20 \%$ de las parroquias los campesinos cultiven patatas.

A mediados del XIX el Diccionario de Madoz refleja cómo en la mitad oriental, en la Galicia del centeno, el tubérculo americano aparece plenamente generalizado, pues en el tercio septentrional de Lugo, en la parte central de las montañas orientales, y la Alta Limia orensana el $100 \%$ de las parroquias recogían patatas. Por contra, en la mitad occidental, en las tierras del maíz, su difusión es mucho menor, especialmente en el sudoeste litoral, en donde menos del $50 \%$, e incluso del $25 \%$ de parroquias cultivaban patatas.

\section{Factores desencadenantes de la expansión de la patata en Galicia}

El momento en que el cultivo de la patata se difunde en los campos y su consumo humano se generaliza, casi siempre coincide con ocasión de crisis agrarias o de situaciones de penuria alimentaria (Eiras, 1998, p. 69), pues en un principio dicho 
Mapa 3. Difusión de la patata en Galicia según los Diccionarios de Miñano (1826-1829) y Madoz (1845-1850). Porcentaje de parroquias en las que se cultivan patatas

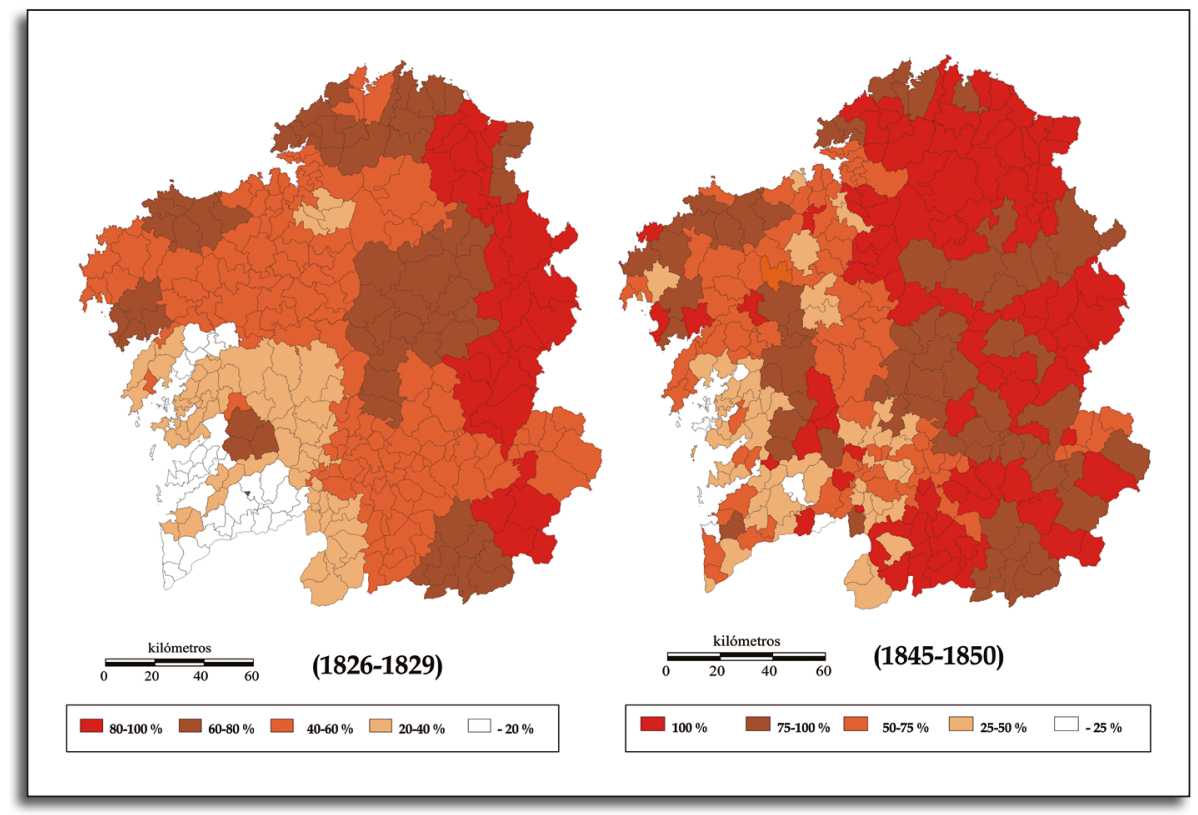

Fuente: Elaboración propia con datos de Miñano, 1826 y Madoz, 1845.

tubérculo era despreciado como alimento para las personas, y sólo es incorporado a la dieta cuando el hambre aprieta más. Así, parece ser que en Galicia son las hambrunas de finales de la década de 1760 las que obligan a los campesinos más desfavorecidos a alimentarse de un tubérculo, que en principio sólo destinaban a cebar los cerdos, y cuyo consumo les repugnaba. Al igual que ocurre en otros territorios europeos como Francia, Países Bajos, Irlanda, Italia, o Portugal, entre otros, en donde la "bella americana" aparece como compañera de la miseria, popularizándose en períodos de hambre o de guerras (Dubuc, 1953; Morineau, 1970; Poitrineau, 1962, p. 328 y 1979; Molinier, 1980, p. 315; Boehler, 1995; Vandenbroeke, 1975; Connel, 1962; Ó Gráda, 1993 y 2015; Salaman, 1991; Georgelin, 1978; Panjek, 1976; Viegas, 1987, pp. 7-24; Sobral, 1994 y 1997, p. 276). Frente a las crisis agrarias, las patatas aportaban beneficios, pues tenían una elevada productividad por unidad de superficie (30-50 por una), y hacían que la subsistencia ya no sólo dependiera de la producción de cereal.

Aunque la patata se conocía con mucha anterioridad y ya se había expandido en algunas zonas altas de Galicia, sin embargo serán las dificultades que acucian a los 
campesinos tras el súbito descenso de la producción cerealera motivado por la crisis de 1769-1770, y la consiguiente hambruna, las que actúan como acicate definitivo, apremiándoles a cultivar el tubérculo, de forma similar a lo que había ocurrido en el XVII con el maíz, que alcanza su verdadera difusión en la Galicia occidental, tras la crisis agraria de 1628-1632 (Pérez García, 1981 y 1992). Realidad de la que se hace eco Pedro Antonio Sánchez: «...se ha visto en el año de sesenta y nueve, en que se perdió la cosecha, reducido todo aquel reino al hambre y a la epidemia, despobladas las aldeas, y parroquias enteras casi desiertas...» (Sánchez, 1973, p. 49). Lucas Labrada, en su Descripción Económica del Reino de Galicia (1804) también destaca el punto de inflexión que dicha crisis supuso para la extensión de las patatas en los campos gallegos:

«...Antes del año de mil setecientos sesenta y ocho en el cual padeció Galicia los azotes del hambre y de la peste, sólo en esta provincia [Mondoñedo] se cultivaban las patatas, y en corta cantidad; pero desde aquella época se han ido extendiendo considerablemente por todas las demás provincias del reino [...]. En todas partes se dan, y es un excelente recurso para suplir la falta de granos, mayormente en Galicia, a donde las lluvias frecuentes son las que, por lo regular, ponen a riesgo las cosechas en el verano, pues estas mismas lluvias sirven para engordar las patatas...» (Labrada, 1971, pp. 21-22).

Son varios los testimonios documentales que corroboran la crecida extensión que experimentó el plantío de patatas en Galicia tras la grave crisis agraria de 1769-1770. En San Salvador de Río Freijo (Ourense), testifican en 1770 que: «...atentos a la escasez de granos que se experimentó en este paraje, se adelantaron los vecinos de la referida feligresia y más llevadores y poseedores de tierra de ella, a sembrar gran cantidad de fruto de castañas mariñas en las principales tierras de dicha feligresia y de considerable extensión...»». Ese mismo año los vecinos de Entrambosríos (Ourense) señalan que «...en ningún tiempo hasta el presente se cogió con más abundancia las nominadas castañas de yndias por sembrarlas como lo hicieron los que tienen señalados por fruto principal y como no executaron dicha siembra asta el año pasado de mil setecientos sesenta y nueve... $\gg^{10}$. Es a partir de este momento cuando las demandas de los perceptores de diezmos exigiendo que los campesinos contribuyan por las patatas, comienzan a proliferar (Mapa 2) (Meijide, 1984); lo que parece indicar una crecida extensión del cultivo, y cierta generalización en los campos abiertos por parte de los campesinos de amplias zonas del interior. 
De nuevo en 1809-1810 la combinación de malas cosechas, epidemias, guerra y saqueo de víveres vuelven a complicar la situación económica de los campesinos (Torija, 2009, p. 629; Catalán y Lanza, 2015, p. 27; Sobral, 1994), que en Galicia viven tiempos de escasez, hambre y mortandad (Eiras, 1990, p. 105; Saavedra, 1979, p. 109; López Álvarez, 1996, p. 91; Sobrado, 2001, p. 340). Puesto que la patata constituía una garantía para paliar la carestía de granos, fue la alternativa para luchar contra el hambre, con lo que su cultivo aumentó notablemente a partir de la Guerra de la Independencia, siendo un detonante para la generalización de su consumo humano (Bilbao, 1984, p. 166; Palanca, 2011; p. 166; Garrabou, 1987, p. 60; Congost, 1989, p. 182; Pérez Samper, 2013). Con el objeto de fomentar el aumento de subsistencias ante la carestía experimentada como consecuencia de la guerra, en 1812 la Secretaría de Estado y Despacho de Hacienda envía un comunicado a la Junta de Defensa de Galicia, recomendando la siembra de varios frutos, sobre todo de «papa o patatas de tierra, especie preciosa [...] que es la que puede socorrernos con mayor seguridad... $»^{11}$.

\section{Iniciativa campesina frente a fomento institucional. Sociología de los cultivadores de patatas}

La introducción y difusión de la patata en Galicia fue fruto prácticamente exclusivo de la iniciativa campesina, determinada por las necesidades de una población rural en crecimiento y mal nutrida, sin que la administración o las instituciones de fomento agrícola gallegas hayan tenido protagonismo alguno. A diferencia de varias Sociedades Económicas de Amigos del País (Asturias, Cantabria, País Vasco, Aragón, Valencia, etc.) que impulsaron la difusión del cultivo de la patata y trataron de lograr su aceptación como alimento humano (Piqueras, 1992a; Riera, 2007; Arias, 2012), instituciones gallegas como la Real Academia de Agricultura del Reino de Galicia (1765-1774), las Sociedades Económicas de Amigos del País de Santiago (1784) y de Lugo (1785), o el Real Consulado de A Coruña (1785), aunque hacen intentos por incentivar entre los labradores otros cultivos (maíz, viñedo, olivos, lino, cáñamo y moreras, etc.), sin embargo, apenas se constata su estímulo del plantío de la patata (Sánchez Rodríguez, 2003).

Hay constancia de algunas medidas oficiales para fomentar el cultivo de patatas, como la Real Orden de 24 de octubre de 1800 dirigida a las autoridades de las siete provincias del Reino de Galicia pidiéndoles la gran conveniencia de fomentar y extender su cultivo, pues: «...Quiere S.M. que se procure fomentar y extender en todas las provincias el cultivo de las patatas el qual, menos expuesto á faltar por las

Archivo Histórico Provincial de Pontevedra (AHPP), Concejo, 82 (132). 
intemperies, y de producto mayor que el de los granos, reúne á estas ventajas la de ser alimento sano para el hombre y no menos para toda clase de animales... $\rangle^{12}$. En 1801 los Ayuntamientos cabeza de provincia notifican a los Justicias de sus respectivas jurisdicciones que procuren expandir lo más posible «...El plantío de batatas para remedio de la carestía actual de granos», e insten a los campesinos para que presten la mayor atención «al fomento de un ramo tan importante». Concejos como el de A Coruña también remiten circulares a los párrocos, para que procuren estimular por todos los medios posibles a los labradores a que adopten el plantío de patatas. Con todo, en la práctica fueron los campesinos los que tuvieron el verdadero protagonismo de la difusión de las patatas en sus campos.

Por lo que respecta a la sociología de la población rural del interior gallego que inicia la plantación de patatas, parece que al principio, son los sectores más pobres del campesinado los que siembran la nueva planta, ante la carestía de cereales, cuando el hambre aprieta. En San Cosme de Nete (Lugo) declaran plantar desde 1755-1758:

«...dichas batatas, las quales también sirben para aiudar a alimentar la gente quando acaecen cosechas escasas de granos [...] sirviendo también las mismas para aiuda del alimento natural de las gentes, expecialmente los pobres que se mantienen en la maior parte con ellas interin les duran probenido de la escasez de otros frutos... $\rangle^{13}$.

En 1770 en Entrambosríos (Ourense) «... solamente los pobres labradores suelen en algunas echarlo con el fruto de las habas y el mijo en aquellas que consideran que sino produce una cosa lo haga la otra para por este medio poder vivir y alimentarse..." 14 . Pero poco a poco, salvadas las trabas iniciales, el cultivo se va difundiendo entre el resto de la población rural. El análisis de los inventarios de bienes de Lugo y Ourense con existencias de patatas (Tabla 3), permite obtener una ligera idea acerca de la sociología de los dueños de explotaciones agrícolas con patatas y su evolución entre 1780-1850. Durante dicho período son principalmente campesinos los que las incluyen entre los productos agrícolas, aunque no exclusivamente, pues también los grupos privilegiados, tanto hidalgos como eclesiásticos van introduciéndolas progresivamente en sus despensas.

Entre 1780-1819 son fundamentalmente campesinos (85-95\%), y algunos hidalgos (5-15\%) los que cuentan con el tubérculo americano entre sus provisiones. Desde 1820-1829 la situación parece haberse equilibrado entre campesinado $(45,7$ $\%)$ y grupos privilegiados (54, $3 \%)$, pues la proporción tanto de hidalgos como de

AHN, Diversos-Colecciones,113, N. 21-1.

ARG, Real Audiencia, Vecinos, 11304/10.

ARG, Real Audiencia, Vecinos, 19922/10. 


\section{Gráfico 5. Evolución de la sociología de los dueños de explotaciones agrícolas con existencias de patatas, 1780-1850. Galicia oriental}

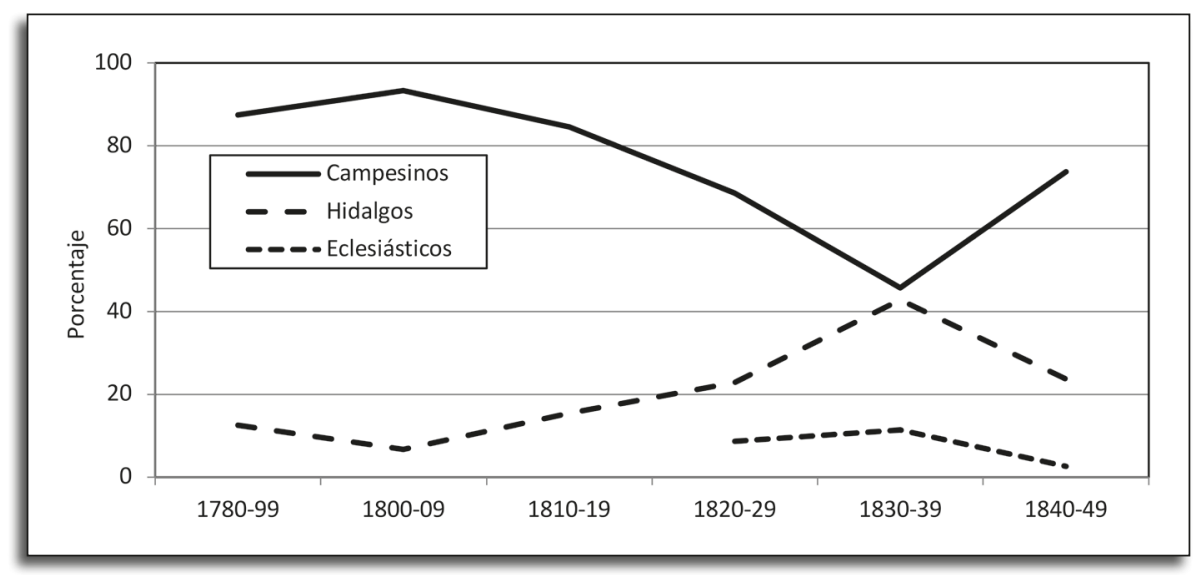

Fuente: Elaboración propia. Documentación citada Tabla 3.

clero parroquial con patatas se ve significativamente incrementada. Ello parece indicar una paulatina aceptación del tubérculo por el conjunto de la sociedad rural del interior gallego, lo que concuerda con las apreciaciones de Miñano en 1826: «...Al principio se dio a los ganados, pero muy en breve sirvió para alimento de la familia del labrador y hoy la vemos hacer papel en las mesas de las personas acomodadas y aun de los ricos...» (Miñano, 1826).

Una vez generalizado su cultivo, la patata deja de ser un recurso exclusivo de campesinos pobres, para aparecer en las explotaciones agrícolas con un nivel medioalto en el contexto de la zona (Gráfico 6), con ganado en propiedad, tanto vacuno como porcino — con medias superiores al conjunto (Gráfico 8)—, y con existencias de cereal.

\section{Consecuencias de la difusión del cultivo de las patatas en Galicia}

En la Galicia interior en la que, como hemos comprobado, la difusión del tubérculo americano fue más temprana e intensa, su progresiva implantación en el sistema de cultivos desde el último tercio del XVIII, tuvo trascendentes consecuencias, al favorecer una reestructuración de la economía rural y el paisaje agrario. Lo que en buena medida contribuye a explicar el papel jugado por la patata en la racionalidad de las dinámicas evolutivas agraria y demográfica de las áreas interiores del territorio gallego a fines del Antiguo Régimen. 


\section{Gráfico 6. Disponibilidad de ganado y cereal de explotaciones agrícolas con patatas según los inventarios post-mortem, 1780-1850. Galicia oriental}

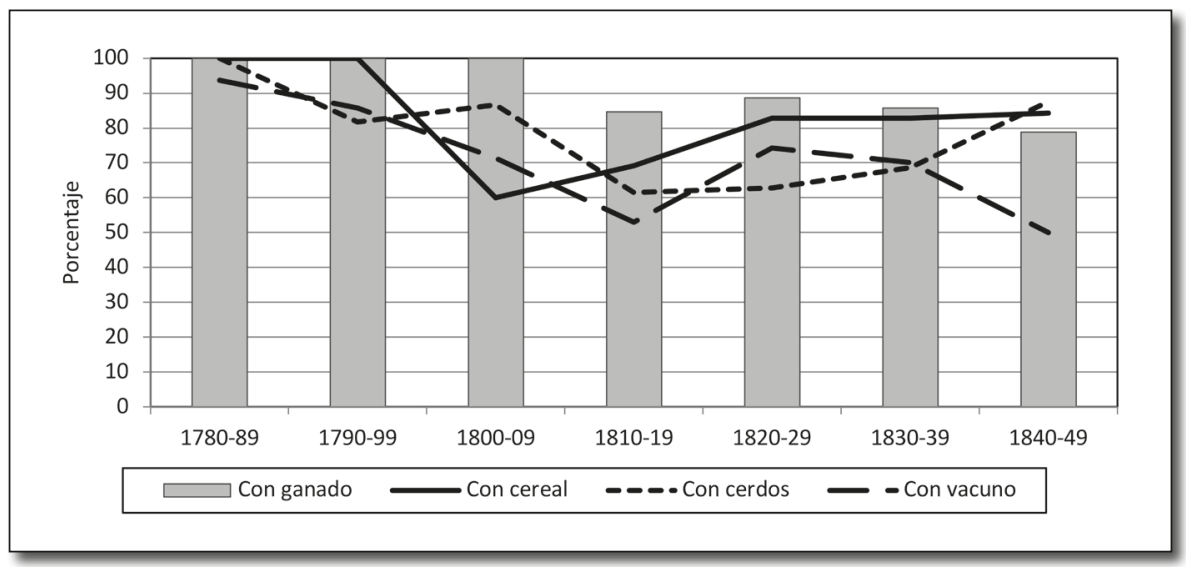

Fuente: Elaboración propia. Documentación citada Tabla 3.

\section{a) Consecuencias económicas. Procesos de reordenación de las explotaciones agrícolas e intensificación agropecuaria}

No cabe duda de que la extensión del cultivo de patatas tuvo una gran repercusión en las economías campesinas del interior gallego, al propiciar reajustes en el sistema de rotaciones, así como procesos de reordenación de las explotaciones agrícolas, que en algunos casos llevaron implícita cierta intensificación agropecuaria. La alternancia de patatas con el centeno permite reducir progresivamente e incluso la supresión del barbecho. Así, en 1798 en Nete (Lugo) «...las batatas se siembran en los villares el año que están de hueco...» $»^{15}$. Operación no exenta de dificultad, pues trastoca muchos de los usos y costumbres del sistema agrario tradicional.

Además, el cultivo de patatas propició reajustes en el sistema de rotaciones, enriqueciéndolas significativamente. Según el Catastro de Ensenada (1753) de Pitelos (Ourense) las tierras de labradío de primera calidad se siembran de linaza y alzado el fruto de «ferraña para dar verde a los ganados», y al año siguiente de «castañas que llaman yndias» ${ }^{16}$, rotación que se repite exactamente igual en 1761, cuando se realizan las Comprobaciones del Catastro ${ }^{17}$. Conjuntamente, en muchas zonas de la Galicia

\footnotetext{
15 ARG, Real Audiencia, Vecinos, 11304/10. Villares o vilares: equivale a agras (unidades de cultivo colectivas con cierre externo, que engloban fincas abiertas).

16 AGS, $C E-R G, 225,529$.

17 AGS, DGR, $1^{a} \cdot R ., 1121 / 15$.
} 
interior la rotación de patatas con centeno, permitía intercalar en la segunda hoja la siembra de nabos, lo que suponía para los labradores dos siembras sucesivas con una sola estercoladura (Saavedra, 1979, p. 46).

La progresiva difusión de patatas en áreas del interior gallego va acompañada de una intensificación de las roturaciones de inculto, pues la nueva planta también se cultivaba en tierras de labradío ganadas al monte o a través de rozas o estivadas realizadas de forma periódica en los comunales (Sobrado, 2001, p. 259; Corbacho, 2017, p. 132). Con su introducción y el notable incremento de los rendimientos, se van haciendo más productivas las explotaciones, lo que permite aligerar la demanda de cereales, y dar impulso a un reordenamiento en la dedicación de las diversas parcelas, que trae consigo cierta intensificación agraria y ganadera. La patata, cultivo de alto potencial productivo, exigía terrenos bien abonados, por lo que su implantación da impulso al proceso comúnmente denominado de acortiñar un agro, es decir, de transformación de tierras de labradío barbechas, organizadas en agros o agras, por parcelas cercadas sin intermisión (cortiñas), que podían dar más de una cosecha anual, intensificando las rotaciones con un mayor riego y abonado, aunque ello exigiese romper las viejas prácticas comunitarias de rotaciones bienales, así como de servidumbres de paso, espigueo y pasto.

Los contratos agrarios de la meseta lucense reflejan cómo los espacios de cultivo intensivo en cortiñas se cuadriplican entre 1790-1849, elevándose a más del 20\%, lo que confirmaría la acentuación del proceso de acortiñar tierras de labradío iniciado desde la década de 1760 (Sobrado, 2001, p. 261). En áreas de la montaña lucense de Burón, Navia, Cervantes o Caurel, las cortiñas podían llegar a constituir más de un 25 $\%$ de la superficie de labranza. Durante el XIX continúan constatándose en la provincia de Lugo numerosos intentos de romper la disciplina de las agras, acotando porciones de éstas, y tratando de reducirlas a cultivo intensivo, sembrando durante el período que antes les correspondía descansar, patatas o nabos con forraje para el ganado, no sin generar enfrentamientos entre vecinos (Villares, 1982, p. 199; Cardesín 1992, p. 75).

El creciente cultivo intensivo y las mayores exigencias de abono para cubrir las nuevas necesidades agrícolas llevaron al campesino a iniciar una paulatina estabulación del ganado a fin de poder aumentar su suministro de estiércol, para lo cual se hizo necesario incrementar la superficie dedicada a prado y tener zonas permanentes de pasto próximas a las explotaciones. Así, en la segunda mitad del XVIII, sobre todo en Mondoñedo, la meseta y área meridional de Lugo, o en la Alta Limia orensana tiene lugar un cambio en la orientación de muchas fincas, que pasan a ser dedicadas a pradería, y la roturación de grandes porciones de monte, transformándolas en prados, al igual que ocurre en otras áreas del norte peninsular (Domínguez, 1988, p. 75 y 1996, p. 236; Barreiro, 1997, p. 28; Lanza, 1991, p. 180 y 2001, p. 86). En el interior 
lucense, entre 1753-1850 la superficie dedicada a pastos pasa de representar alrededor del $13 \%$ al $32 \%$. Tendencia que corroboran los contratos agrarios e inventarios post-mortem, que revelan a partir de la década de 1760 un significativo aumento de las explotaciones con existencias de hierba en sus eras — del orden del $50 \%$-, así como del número de carros por explotación. En la comarca meridional lucense de Chantada la extensión de prado entre 1753-1880 llega a triplicarse, alcanzando del orden del 25-30 \% del total cultivado (Sobrado, 2001, p. 264; Villares, 1982, p. 194).

El creciente interés de los campesinos por las tierras dedicadas a pasto, hace que los prados pasen a constituir las parcelas más apetecibles y objeto de compraventa, llegando a triplicar su cotización entre 1760-1850 en tierras lucenses (Sobrado, 2001, p. 263). El avance de las praderías modifica algunas de las estructuras tradicionales que regían en el campo, provocando una intensificación de la litigiosidad entre vecinos, tanto por problemas de servidumbres colectivas, conducción de aguas, cercamientos... ${ }^{18}$, como con los rentistas por diezmos de la hierba, que se hace más intensa a partir del último tercio del XVIII (Villares, 1982, p. 193; Candal, 1993, p. 92; Pérez García, 2004; Saavedra, 2008, p. 184 y 2009, p. 70; Rey, 2012, p. 60).

Desde finales del XVIII, y fundamentalmente en el XIX, el aumento de la superficie de prado, junto con el creciente cultivo de plantas forrajeras, como el nabo, y las propias patatas, posibilitó una mejor alimentación del ganado, así como la progresiva transformación de una ganadería tradicionalmente extensiva que pastaba suelta en el monte, en una explotación más intensiva de la cabaña ganadera. Los inventarios de la meseta lucense muestran una creciente disponibilidad de estiércol en las explotaciones agrícolas entre 1760-1850, a pesar del descenso constatado del número de cabezas de ganado por vecino - del orden del $30 \%$ - lo que podría indicar una tendencia hacia una mayor estabulación del ganado, pues los mayores rendimientos que este ofrecía, y las menores pérdidas de reses en el monte, hacían innecesario a los campesinos criar el mismo número de cabezas que bajo el anterior sistema de ganadería extensiva.

En todo caso, a pesar de que en Galicia se constata cierta intensificación pecuaria, y a partir del XVIII se inicia una creciente mercantilización hacia Castilla y Portugal, y más tarde en la segunda mitad del XIX hacia Inglaterra (Eiras, 2008, p. 587; Carmona, 1982), estas pequeñas mudanzas distan bastante de los procesos de especialización y transformación pecuaria experimentados en otras zonas de Europa (Madeline y Moriceau, 2006); pues en Galicia la especialización ganadera no se consolida hasta el primer tercio del s. XX (Saavedra, 2008, p. 192 y 2008b, p. 766; Fernández Prieto, 2000). La mayor participación en el mercado a través de respuestas adaptativas como

$18 \quad$ Sobre el papel de las comunidades rurales en la defensa de los derechos históricos sobre el agua (Rubio, 1997). 
las migraciones estacionales y temporales, o la especialización ganadera y forestal, fueron factores que sin duda contribuyeron a mejorar los niveles de vida de los campesinos gallegos ya en el período contemporáneo (Domínguez, 2002, p. 320).

El proceso de intensificación agropecuaria experimentado entre fines del XVIII y la primera mitad del XIX, con la introducción de nuevos cultivos, el aumento de la superficie de cortiñas y prados, así como las mejoras introducidas en las rotaciones, aunque modesto en comparación con el experimentado en otros ámbitos europeos (Overton, 1996; Allen, 1992 y 2000; Clark, 2002; Lains y Pinilla, 2009; Burnette, 2014), contribuye a incrementar los rendimientos agrícolas, con lo que las necesidades familiares están cubiertas con explotaciones más pequeñas. De hecho, tanto en tierras lucenses como mindonienses se observa una reducción del tamaño de las explotaciones campesinas, de en torno al 20-25 \% y entre un 10-40 \%, respectivamente (Sobrado, 2001, p. 270; Saavedra, 1985, p. 219). Además, dichas transformaciones agrarias, supusieron una profunda mutación en el paisaje agrario de la Galicia interior, contribuyendo a gestar la fijación de la fisonomía de los paisajes forestales y agroganaderos que en el período contemporáneo habrán de caracterizar a esta zona del terriorio gallego (Sobrado, 2010; Saavedra, 2008b y 2015), en la línea del resto de la España cantábrica y noratlántica.

\section{b) Consecuencias sociales. Mejora de las condiciones de vida del campesinado}

En la Galicia interior la diversificación de los cultivos que posibilitó la extensión de las patatas, y sus mayores rendimientos por unidad de superficie, así como el proceso de intensificación agropecuaria que estimuló su implantación, ayudaron, sin duda, a aliviar la situación de muchos campesinos, favoreciendo una substancial mejora de sus condiciones de vida ${ }^{19}$. Desde el último tercio del XVIII, la humilde patata parece haber contribuido a mejorar doblemente la alimentación campesina (Meyer, 1980, p. 31), pues, dada la inicial y recurrente repugnancia popular hacia el tubérculo, seguramente más que a través de su consumo directo, en un principio lo hizo de un modo indirecto. No hay que olvidar que la patata se introduce inicialmente con finalidades básicamente forrajeras (Durán, 1997, p. 300), mejorando la manutención del ganado, sobre todo porcino, mediante su ceba; tal y como señalan múltiples testimonios de la época.

En la Galicia interior los cerdos se alimentaban fundamentalmente en el monte y con los desperdicios domésticos, o con hortalizas, nabos, castañas y cereal20. A par-

\footnotetext{
19 Acerca de la interrrelación entre crecimiento agrícola y mejora de las condiciones de vida del campesinado: (Dennison y Simpson, 2010; Olsson y Svensson, 2011; Hillbom y Svensson, 2013). 
tir de 1770, con las patatas la ceba de cerdos experimenta una notable mejora, pues hacen posible su estabulación y ahorran el empleo de granos (centeno, avenas, etc.). En 1798 en San Cosme de Nete (Lugo): «....sirviendose todos de las batatas para la cria y ceba de los ganados de cerda $[. .$.$] dicho fruto de batatas sirbe para cebar la carne$ de cerda, con cuio uso se aorra mucha mas arina que con los nabos con que antes se cebava... $\gg^{21}$. El abate Rozier en su Diccionario Universal de Agricultura (1781-1800) destacaba las excelencias para el forraje del ganado y la alimentación humana de las variedades de patatas cultivadas en Galicia: «...la gallega gorda se debe preferir para el sustento de los animales y la preparación de la harina, porque es más fecunda y la más vigorosa de todas [...], la gallega larga [...] deben destinarse para la mesa...» (Rozier, 1797, p. 448).

En el último tercio del XVIII y primeras décadas del XIX en tierras del interior gallego se constata una menor cabaña porcina por explotación, pero de superior calidad, crecientemente estabulada y mejor alimentada. Los inventarios de la meseta y la montaña lucense (Cervantes) o de diversas comarcas de Ourense, como Xinzo, Verín o Celanova reflejan una progresiva reducción de la media de ganado porcino por explotación entre 1760-1850, que pasaría de unas 3-5 a 2-3 cabezas (Sobrado, 2001; Rodríguez Fernández, 2006), aunque el aumento del número de vecinos hace que la cabaña porcina lejos de verse reducida aumente significativamente entre 1753-1865. En Viana do Bolo (Ourense), la introducción de patatas y la extensión de castaños parecen explicar un ligero incremento de la media de cabezas de cerda por explotación (Quiroga, 1988, p. 59)22.

En los siglos XVII-XVIII en la documentación de la Galicia oriental abundan los testimonios de «tocinos flacos y pequeños» ${ }^{23}$, con una media de entre 10-15 libras de peso, y untos que apenas alcanzan las 3,5-5 libras, con lo que un puerco sacrificado no acostumbraba a superar los 60-70 kilogramos (Villares, 1973, p. 71). En la primera mitad del XIX, los inventarios de tierras lucenses y orensanas reflejan la existencia en las casas de tocinos y untos de mayor tamaño (20-25 y 6-7 libras respectivamente) $)^{24}$.

La patata parece tener un gran protagonismo en la mejora de la ceba de cerdos y ayudaría a explicar la evolución al alza del peso medio de sus derivados cárnicos (tocinos y untos), — del orden del 30-35 \% - (Tabla 4), que estaría indicando un significativo incremento del tamaño y peso por animal. El gráfico 7 constata cierta correlación entre la evolución de las existencias de patatas sobre el conjunto de productos

\footnotetext{
$21 \quad$ ARG, Real Audiencia, Vecinos, 11304/10.

22 Sobre la correlación entre abundancia de castañas y densidad de porcino en el Bierzo leonés (Pérez Álvarez, 2004, p. 801).

23 AHPO, Protocolos, 1560.

24 AHPL, Protocolos, 6623/5, fol. 21.
} 
Tabla 4. Evolución del peso medio de untos y tocinos (libras) según los inventarios post-mortem. Viana-Xinzo-Verín (Ourense) y Centro Lugo-Cervantes (Lugo), 1650-1850

\begin{tabular}{|l|c|c|c|c|}
\hline Viana do Bolo & Casos & Peso medio untos & Casos & Peso medio tocinos \\
\hline $1750-1759$ & 10 & 4,85 & 26 & 13,60 \\
\hline $1800-1819$ & 7 & 6,28 & 14 & 19,96 \\
\hline Xinzo de Limia & & & & \\
\hline $1650-1699$ & 14 & 4,00 & 3 & 15,0 \\
\hline $1700-1749$ & 37 & 3,85 & 62 & 17,6 \\
\hline $1750-1799$ & 17 & 5,11 & 55,5 & 22,2 \\
\hline $1800-1850$ & 47 & 6,05 & 65,5 & 25,9 \\
\hline Verín & & & & 15,7 \\
\hline $1750-1799$ & 19 & 4,5 & 62 & 19,6 \\
\hline $1800-1850$ & 7 & 7,4 & 12 & 14,72 \\
\hline Centro Lugo & 13 & 3,53 & 11 & 8,81 \\
\hline $1650-1699$ & 122 & 3,18 & 27 & 11,70 \\
\hline $1700-1749$ & 43 & 3,50 & 58,5 & 19,30 \\
\hline $1750-1799$ & 12 & 4,40 & 40 & 14,31 \\
\hline $1800-1850$ & & & & 18,83 \\
\hline Cervantes & 19 & 4,3 & 72 & \\
\hline $1750-1799$ & 17 & 5,4 & 129 & 38 \\
\hline $1800-1850$ & 384 & & & \\
\hline Total & $198, p, 60$, & &
\end{tabular}

Fuente: Viana do Bolo (Quiroga, 1988, p. 60). Resto datos elaboración propia: documentación citada Tabla 3.

agrarios en las despensas de las casas del interior lucense y el significativo incremento del peso medio de los tocinos y su disponibilidad total por explotación.

Además, los inventarios de la meseta y montaña lucense y de la comarca orensana de A Limia indican que, a pesar de la tendencia global a la paulatina reducción de las medias de porcino por vecino ya comentada, en aquellas explotaciones que entre finales del XVIII y mediados del XIX cuentan con existencias de patatas, parece observarse una propensión a la cría de un mayor número de cerdos que en el conjunto de las explotaciones de la zona (Gráfico 8). Es el caso de Manuel Fernández, de Pousada (Lugo), que en 1786 tiene 40 fanegas de patatas y 15 cabezas de porcino ${ }^{25}$. Dicha correlación seguramente podría indicar, en muchos casos, un uso preferente por parte de los campesinos de las patatas como forraje para sus animales, en la línea de lo que ocurría en otras zonas de la Península o de Europa como Irlanda, en las que una parte notable de la producción se destinaba al engorde del ganado (Congost, 1989; Mokyr, 1981, p. 27).

Contrastando los datos del Censo ganadero de la Corona de Castilla (1752) con los del Censo de la Ganadería de España (1865), se observa que en Galicia a diferencia del resto de cabañas, la porcina mantiene su volumen, e incluso lo incrementa

25 AHPL, Protocolos, 603/6, fol. 86 y 803/4. 
Gráfico 7. Correlación entre la evolución del porcentaje de patatas sobre el total de existencias de productos agrarios en los inventarios post-mortem y la evolución del peso medio de tocinos (en libras) y su disponibilidad por explotación. Interior lucense, 1750-1850

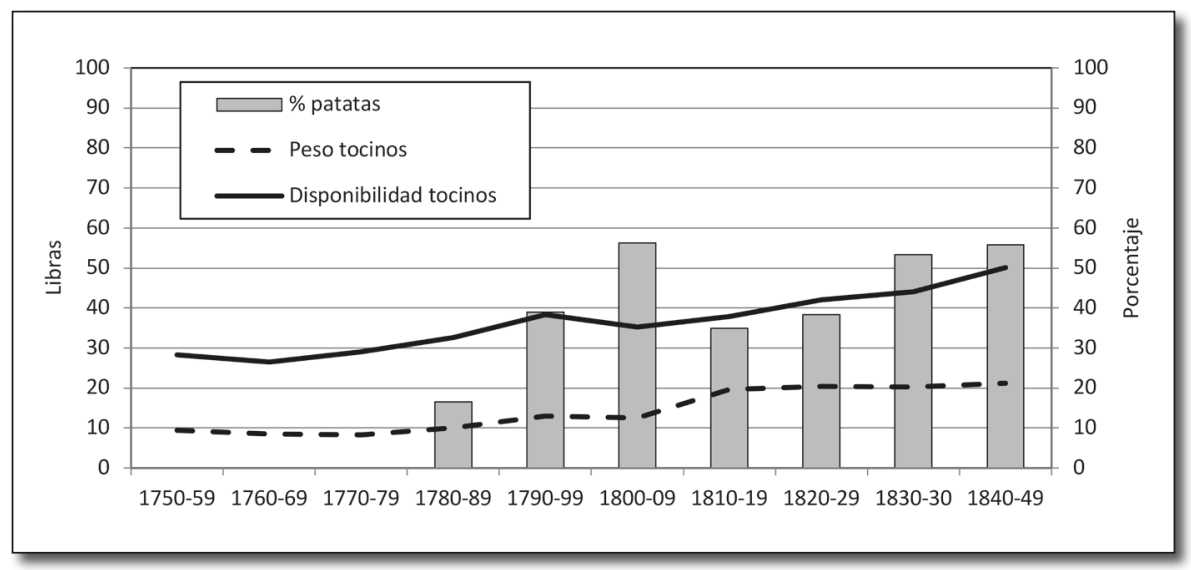

Fuente: AHPL, Protocolos, 350, 502, 506-509, 599-553, 593-597, 601-603, 623-625, 690-693, 706-708, 716-718, 802-808, 2458, 2475, 2501.

Gráfico 8. Media de cabezas de ganado porcino por explotación según los inventarios, 1790-1850

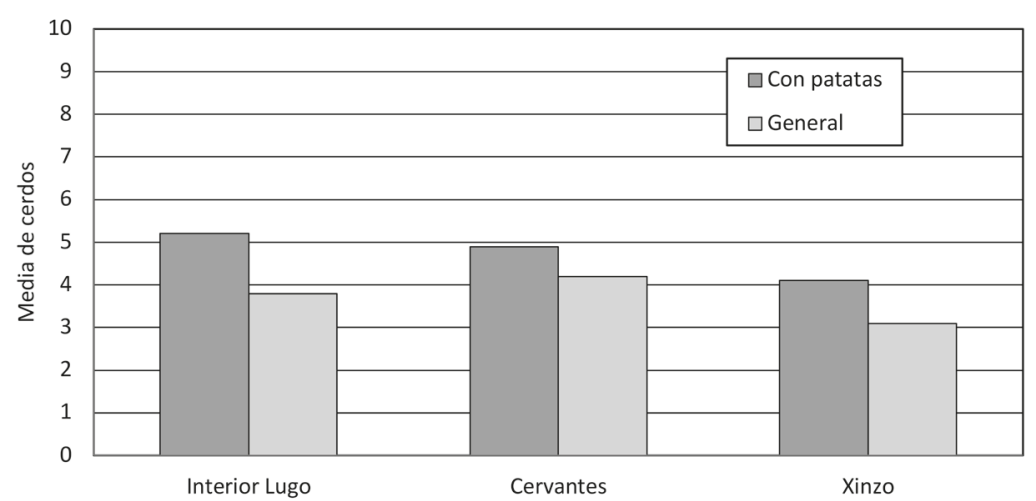

Fuente: Elaboración propia. Documentación citada en Tabla 3. 
ligeramente, ganando en "peso vivo" ganadero, al igual que ocurre en tierras leonesas (García Sanz, 1994, p. 104; Pérez Álvarez, 2004, p. 803); pudiendo comprobarse cómo las provincias interiores de Ourense y Lugo concentran casi el $60 \%$ del total de la cabaña porcina gallega, así como los partidos judiciales que presentan una mayor media de cabezas por propietario — Verín: 4,52 y Xinzo de Limia: 4,0; Sarria: 4,2; Villalba: 3,3; As Nogais: 3,2; Quiroga: 3,0-, allí donde patatas y castañas contribuyen a la ceba de cerdos.

La patata junto con el incremento de las praderías, también tuvo que redundar en una mejor alimentación de la cabaña bovina, lo que se traduce en una superior calidad de las reses (Pérez García, 2007, p. 106). En muchas áreas de Galicia en los siglos XVI-XVII la cabaña ganadera extensiva, en libertad en el monte, era abundante pero famélica y raquítica, de escaso peso. Tras procesos de progresiva estabulación, los campesinos del XVIII disponían de menos reses que sus antepasados, pero éstas eran de mejor calidad. Así, los bueyes que se sacrificaban en la carnicería de Ribadeo a finales del XVIII pesaban el doble que los que se mataban a fines del XVI (Saavedra, 1985, p. 260).

Una vez superadas las resistencias que cultivos americanos como el maíz o la patata encontraron para introducirse en la dieta de los europeos (Pérez Samper, 2014, p. 29; Levi, 2014, p. 106), las patatas empiezan a adquirir poco a poco protagonismo en la alimentación directa del campesinado gallego. Dado que su incorporación al sustento cotidiano de la población rural se produjo coincidiendo con los períodos de máxima carestía de cereales, a buen seguro permitió paliar la falta de granos, aliviando las estrecheces de muchos campesinos. Salvada la repugnancia inicial de la población, el nuevo tubérculo va dejando de ser alimento exclusivo del pobre, para generalizarse al resto de la sociedad rural.

Aunque hubo varios intentos de panificar las patatas en diversos puntos de la Península, en general éstos fracasaron (Pérez Samper, 2009, p. 22), por lo que en Galicia el tubérculo acostumbraba a ser consumido por los campesinos asado en las brasas, cocido o formando parte del popular caldo. En un Informe del Diputado General del Reino de Galicia de 1798 se confirma la generalización del caldo de nabizas y patatas como alimento del que echan mano los campesinos para su sustento: «...se recurrió al fomento de la batata de que con el auxilio de los navos y naviza que estas producen, hacen su alimento todos los labradores mas de la tercera parte del año, engrasando la batata con una corta porción de leche...» ${ }^{26}$. En el transcurso del ochocientos abundan los testimonios que incluyen a las patatas en la dieta cotidiana de los campesinos gallegos. Así, según José María Gil en 1839 en las aldeas era habitual el 
consumo de papas de maíz, berzas y patatas (Gil, 1839, p. 346). A mediados del XIX el campesinado gallego se alimentaba «...con patatas cocidas, muchas veces sin sal, con un caldo de verdura...» (Domínguez, 1996, p. 146).

Pero, por otro lado, las cosechas de patatas también contribuyen a reducir el volumen de cereal y castañas que antes consumía el ganado, ampliando de este modo la parte que se dedicaba a la alimentación humana. No hay que olvidar que en las zonas ricas en sotos de la Galicia interior los campesinos, en muchos casos, preferían como alimento las verdaderas castañas de los castiñeiros a las castañas de tierra o patatas (Bouhier, 2001, p. 744).

\section{c) Consecuencias demográficas de la difusión del cultivo de la patata}

$\mathrm{Al}$ contribuir a mejorar directa e indirectamente las condiciones de vida de los campesinos gallegos, la difusión de las patatas tiene una serie de repercusiones demográficas, entre las que cabe destacar la suavización de las crisis de subsistencias (al no depender exclusivamente de los cereales), así como la estimulación de la nupcialidad y de la natalidad; hasta el punto de jugar, sin duda, un papel importante como motor del crecimiento de la población de la Galicia interior en las últimas décadas del XVIII y primera mitad del XIX.

En una economía agraria como la gallega, con bajos niveles de consumo básico y débil grado de mercantilización, la siembra del tubérculo contribuye a fortalecer la práctica del policultivo, lo que supone una estrategia de reducción de riegos ante posibles períodos de carestía, permitiendo minimizar los problemas de déficits alimentarios (Domínguez, 2002, p. 308). Igualmente, las condiciones más favorables de la agricultura del interior desde el último cuarto del XVIII, con el aumento de productividad por la intensificación agropecuaria experimentada, impulsan la reducción del tamaño medio de las explotaciones y una reordenación de las estructuras familiares entre 1753-1854 — que tienden a diluir su complejidad (Sobrado, 2011, p. 398)—, lo que por ende estimularía la nupcialidad, rebajando un poco el elevado celibato tradicional en tierras del interior y la montaña. Tendencia que ya parece reflejar el censo de 1787 en algunas zonas como Burón (Lugo), en las que las mujeres tienen mayores posibilidades de contraer matrimonio que varias décadas antes (Eiras, 1990a, p. 155).

Por otra parte, la patata aunque proporcione menos calorías que el centeno, cultivo básico del sistema agrario del interior gallego, con su gran rendimiento (alrededor de 7 veces más elevado) hace posible la alimentación de un mayor número de personas en igual superficie de cultivo (Chevet, 1994, p. 110; Campbell, 1996, p. 264). Ello redunda en estimular la fecundidad, favoreciendo el incremento del número de nacimientos, tanto en el seno del matrimonio como fuera de él. Lo que configura uno de los principales factores explicativos del espectacular crecimiento demográfico ex- 
perimentado en la montaña mindoniense y en tierras del centro y áreas orientales de la antigua provincia de Lugo a partir del último cuarto del XVIII. En 1776, el propio Adam Smith hacía referencia a los elevados rendimientos de la patata como agente de dinamización económica y demográfica:

\begin{abstract}
«...Si este vegetable se hubiese extendido en Europa como el arroz en algunos paises, y se llegase a hacer alimento común del pueblo, ocuparia las mismas tierras de labor que ahora el trigo y otras especies de granos, con la ventaja de que una misma cantidad de tierra cultivada podría mantener mucho mayor número de gentes: y sustentándose con ellas generalmente los trabajadores del campo quedaria para el dueño un sobrante mucho mayor que en las otras especies después de satisfechos los salarios del trabajo, y las ganancias del fondo empleado en su cultivo: la población se aumentaria, y subirian las rentas a más alta proporción...» (Smith, 1794, p. 278).
\end{abstract}

Sobre el protagonismo de la patata como factor determinante del crecimiento demográfico en Galicia, destaca el testimonio de Miñano (1826): «...no me olvidaré de colocar en el número de los agentes del aumento de población de este país a la humilde patata, que ha ido propagandose más tarde y con más lentitud que el maíz...», en virtud de «...la mucha cantidad de materia nutritiva que produce, comparada con otras semillas...» (Miñano, 1826, IV, pp. 255-258).

Los efectos de la interacción recíproca del incremento de la producción agrícola sobre el crecimiento demográfico, avivados por el nuevo cultivo, parecen constatarse en las provincias interiores de Lugo y Ourense, tanto a través de los censos de población de 1787 y 1860, que reflejan tasas de crecimiento superiores a la media general gallega en el último tercio del XVIII y primera mitad del XIX, como de las series parroquiales (Eiras, 1996, p. 109). En áreas de la Galicia oriental en las que la patata se había generalizado como el interior mindoniense, la meseta y montaña lucense, o la Alta Limia orensana se confirma un crecimiento intenso de los bautizados entre 1770-1850, del orden del 60-70\% (Gráfico 9).

La provincia de Lugo es la que experimenta el mayor crecimiento demográfico entre 1787-1860 (Eiras, 1996, p. 326). Los índices decenales de bautizados de Muras, en la montaña mindoniense, muestran un aumento del 79,5\% entre $1770-1830$, lo que supone un espectacular casi 10 por mil anual. Tendencia muy similar a la observada en parroquias del interior y la montaña lucense, como la de Freixo (Burón), cuyos bautismos son casi un 70 \% más numerosos entre 1770-1850 (Eiras, 1992a, p. 152; Saavedra, 1985, p. 84 y 1979, p. 109). En el centro y sur de Ourense, en las comarcas de A Limia y Verín, también se observa un intenso crecimiento entre 1770-1850, del orden de más del $63 \%$ para la Alta Limia, y del 35-55 \% en el valle y la montaña de Monterrey. Sin embargo, en las tierras más occidentales de Cea y de Celanova, en 
Gráfico 9. Evolución índices decenales de bautizados.

Galicia septentrional y oriental, $1600-1850$

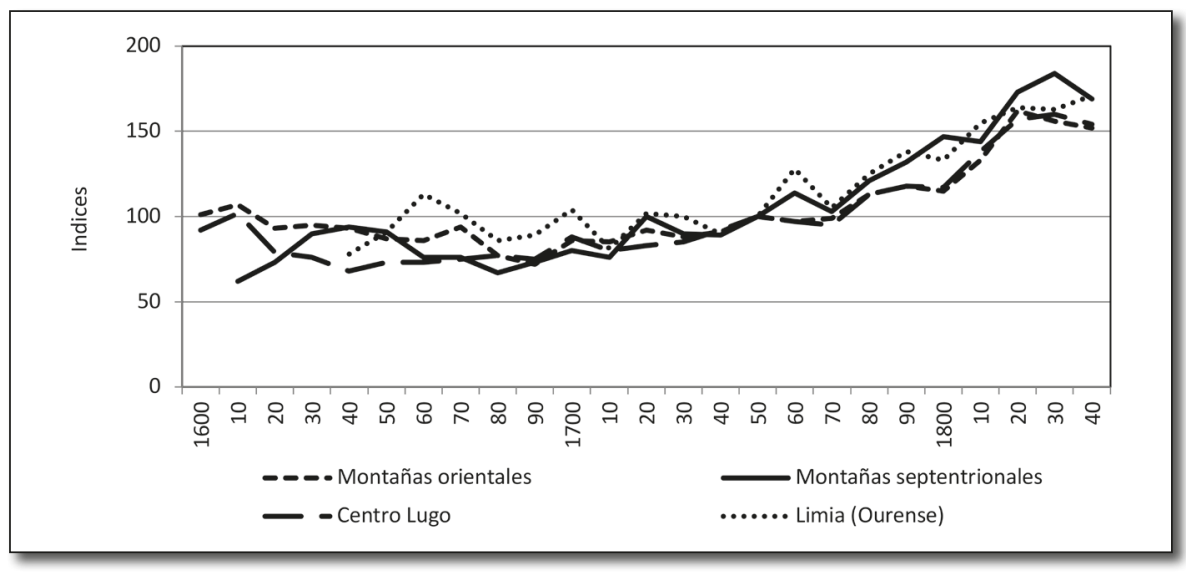

Fuente: Elaboración propia con datos de Ferreiro, 1981; Saavedra, 1993; Sobrado, 2011.

donde las patatas tardaron mucho más en reemplazar al maíz, el ritmo de crecimiento demográfico es mucho más pausado (15-30 \%) (Ferreiro, 1981; González Abellás, 1999, pp. 11-50; Rodríguez Fernández, 1999). Empero, en la Galicia Occidental, allí donde la patata había tenido una extensión mucho más tardía y menos intensa, los niveles de crecimiento demográfico a lo largo del último cuarto del XVIII y primera mitad del XIX son bastante más modestos, en algunos casos incluso negativos.

La evolución de los índices decenales de bautismos de la Jurisdicción de Folgoso, en la comarca de Órdenes, de la Tierra de Santiago, o de la comarca del Salnés, en las Rías Bajas, constatan cómo entre 1770-1850 el crecimiento demográfico apenas alcanza el 20-25\%, mientras que la comarca de Xallas incluso experimenta un estancamiento (Gráfico 10).

\section{Conclusiones}

Nos hemos aproximado a la progresión del cultivo de la patata, así como al papel que jugó en la racionalidad de las dinámicas evolutivas agraria y demográfica de las áreas interiores del territorio gallego entre 1750-1850. La implantación a finales del Antiguo Régimen en los campos gallegos de nuevos productos de origen americano de gran productividad como las patatas, aunque no cambiaron de forma revolucionaria el tradicional sistema agrario, sí contribuyeron a mejorar la situación de muchos campesinos de las tierras altas y centeneras menos favorecidas de la Galicia interior. 
Gráfico 10. Evolución índices decenales de bautizados.

Galicia occidental, 1600-1850

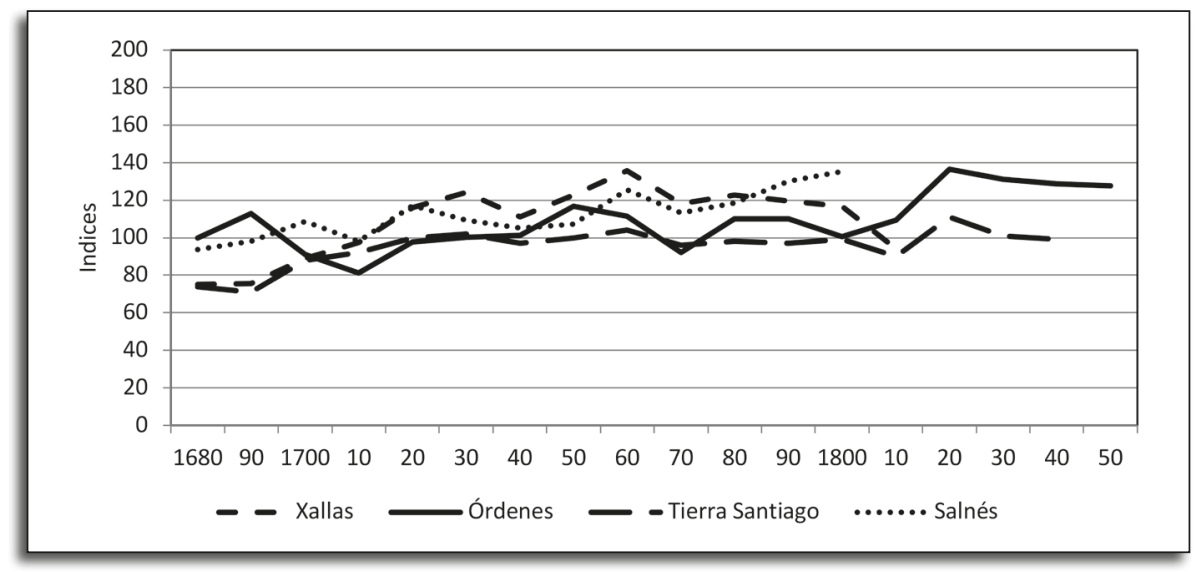

Fuente: Elaboración propia con datos de Barreiro, 1977; Sandoval, 1999; Saavedra, 1993; Pérez García, 1979.

Si bien en muchas zonas gallegas la generalización de la patata no tendrá lugar hasta bien entrado el siglo XIX, a partir del último tercio del XVIII en algunas áreas de la Galicia oriental la nueva planta se convierte en producto principal, alcanzando importantes repercusiones económicas, sociales y demográficas. Su difusión tuvo destacadas consecuencias para las economías campesinas y el paisaje agrario, pues una vez sorteadas las trabas iniciales, el tubérculo americano permitió superar la monotonía del tradicional sistema agrario, enriqueciendo las rotaciones, y contribuyendo a la reordenación de las explotaciones agrícolas de la Galicia interior, posibilitando cierta intensificación agropecuaria. Todo ello, permitió afrontar las carestías de granos, con mayor seguridad, amortiguando las hambrunas y favoreciendo, doblemente la nutrición de los campesinos del interior: tanto por vía indirecta (a través de la mejora de la ceba de ganado, y menor gasto de grano y castañas), como de forma directa, diversificando la dieta por medio del creciente consumo humano del tubérculo.

La intensificación agropecuaria que propició su introducción, seguramente contribuyó a mejorar las condiciones de vida del campesinado, convirtiéndose en uno de los principales factores responsables del vigoroso crecimiento demográfico experimentado en el último cuarto del XVIII y primeras décadas del XIX en la Galicia interior. 


\section{Bibliografía}

Allen, Robert (1992), Enclosure and the Yeoman: The Agricultural Development of the South Midlands 1450-1850, Oxford, University Press.

Allen, Robert (2000), "Economic Structure and Agricultural Productivity in Europe, 1300-1800", European Review of Economic History, 3, pp. 1-25. https://doi. org/10.1017/S1361491600000125

ANES, Gonzalo (1985), “La Asturias preindustrial”, en Fernández, Roberto (ed.). España en el siglo XVIII, Barcelona, Crítica, pp. 505-535.

ARIAS DE SAAVEDRA AlíAS, Inmaculada (2012), "Las sociedades económicas de amigos del país: proyecto y realidad en la España de la Ilustración”, Obradoiro de Historia Moderna, 21, pp. 219-245. https://doi.org/10.15304/ohm.21.689

Ardit, Manuel (2007), "La Historia rural de la España oriental durante la Edad Moderna: un estado de la cuestión”, Studia Historica. Historia Moderna, 29, pp. 47-82.

Barreiro Mallón, Baudilio (1977), La jurisdicción de Xallas en el XVIII. Población, sociedad y economía, Santiago, Universidad.

Barreiro Mallón, Baudilio (1997), "Montes comunales y vida campesina en las regiones cantábricas”, Stvdia Histórica. Historia Moderna, 16, pp. 17-56.

Bilbao Bilbao, Luis María; Fernández de Pinedo, Emiliano (1984), "La producción agrícola en el País Vasco (1537-1850)", Vasconia: Cuadernos de HistoriaGeografia, 2, pp. 83-198.

BoeHLer, Jean Michel (1995), La paysannerie de la plaine d'Alsace (1648-1789), Strasbourg, Presses universitaires.

BouHier, Abel (2001), Galicia. Ensaio xeográfico de análise e interpretación dun vello complexo agrario, Santiago, Xunta Galicia.

BurnetTe, Joyce (2014), «Agriculture, 1700-1870», en Floud, Roderick et alii, The Economic History of Modern Britain, 1700-1870, Cambridge, C.U.P., pp. 89-117. https://doi.org/10.1017/CHO9781139815017.004

Brines i Blasco, Joan (1996), "La introducción del cultivo de la patata en el país Valenciano", Papeles de Geografia, 23-24, pp. 63-69.

CAmpbell, Bruce M. S., Overton, Marc, HefFer, J., BéAur, Gérard (1996), «Production et productivité dans l'agriculture anglaise, 1086-1871», Histoire \& Mesure, vol. 11, 3-4, pp. 255-297. https://doi.org/10.3406/hism.1996.1476

CAndal GonzÁlez, Xosé Manuel (1993), "Pleitos de aguas en la Audiencia coruñesa durante el XVIII”, Obradoiro de Historia Moderna, 2, pp. 85-103. https://doi. org/10.15304/ohm.2.528 
CARdesín DíAz, José María (1992), Tierra, trabajo y reproducción social en una aldea gallega (XVIII-XIX): muerte de unos, vida de otros, Bilbao, Ministerio Agricultura, Pesca y Alimentación.

CARmona BAdíA, Xoan (1982), "Sobre as orixes da orientación exportadora na producción bovina galega. As exportacións a Inglaterra na segunda metade do século XIX”, Grial, pp. 169-206.

Catalán Martínez, Elena, Lanza García, Ramón (2015), “Alimentación, carestías y crisis de mortalidad en la España cantábrica (1680-1860)”, Historia Agraria, 67, pp. 11-42.

Clark, Gregory (2002), The Agricultural Revolution and the Industrial Revolution: England, 1500-1912, Unpublished manuscript.

Connel, Kenneth H. (1962), “The popato in Irland”, Past and Present, 23, pp. 57-71. https://doi.org/10.1093/past/23.1.57

Congost, Rosa (1989), "Presión demográfica, relaciones de clase y producción agrícola en la región de Gerona (1768-1862)", Agricultura y Sociedad, 50, pp. 155-186.

Corbacho GonzÁlez, Beatriz (2017), Intensification of a peasant agriculture and soil fertility in an atlantic territory: Galicia, 1750-1900, Santiago (tesis de doctorado).

Cura de Linares (1797-1799), Semanario de Agricultura dirigido a los Párrocos, Madrid, Imprenta de Villalpando.

CHEvet, Jean-Michel (1994), «Production et productivité: un modèle de développement économique des campagnes de la région parisienne aux XVIIIe et XIXe siècles», Histoire \& Mesure, 9, 1-2, pp. 101-145. https://doi.org/10.3406/hism.1994.1430

Dennison, Tracy, Simpson, James (2010), «Agriculture», en Broadberry, Stephen; O'Rourke, Kevin, The Cambridge Economic History of Modern Europe, 1700-1870, Cambridge, C.U.P., pp. 147-163. https://doi.org/10.1017/ CBO9780511794834.008

Domínguez MarTín, Rafael (1988), Actividades comerciales y transformaciones agrarias en Cantabria, 1750-1850, Santander, Universidad.

Domínguez Martín, Rafael (1996), El campesinado adaptativo. Campesinos y mercado en el norte de España, 1750-1880, Santander, Universidad/Asamblea Regional.

Domínguez Martín, Rafael (2002), “Autoconsumo, mercantilización y niveles de vida campesinos en la España atlántica, 1750-1930. Algunas hipótesis a contracorriente", en Martínez Carrión, José Miguel (ed.), El nivel de vida en la España rural, siglos XVIII-XX, Alicante, Universidad, pp. 287-320.

Dubuc, André (1953), «La culture de la pomme de terre en Normandie avant et depuis Parmentier», Annales de Normandie, 1, pp. 50-68. https://doi.org/10.3406/ annor.1953.4239 
DURÁN I CAIXAL, Monserrat (1997), "La introducción de los cultivos americanos en Cataluña (XVI-XVIII)", en Morilla Critz, José et alii (eds.), Impactos exteriores sobre el mundo rural mediterráneo, Madrid, Ministerio Agricultura, Pesca y Alimentación, pp. 289-306.

EIRAs RoEL, Antonio (1990), «Dîme et mouvement du produit agricole en Galice, 1600-1837», en Estudios sobre agricultura y población en la España moderna, Santiago, Tórculo, pp. 105-110.

EIRAs Roel, Antonio (1990a), "Evolución agraria y crecimiento demográfico en España, XVI-XVII", en Estudios sobre agricultura y población en la España moderna, Santiago, Tórculo, pp. 131-185.

EIRas Roel, Antonio (1996), La Población de Galicia, 1700-1860, Santiago, Fundación Caixa Galicia.

EIRAs RoEL, Antonio (1998), "Los productos alimentarios de Ultramar en la agricultura de los países mediterráneos”, Obradoiro de Historia Moderna, 7, pp. 27-88. https://doi.org/10.15304/ohm.7.920

Eiras Roel, Antonio (2008), “Galicia en el sistema comercial español a finales del siglo XVIII”, en Franch Benavent, Rafael y Benítez Sánchez-Blanco, Ricardo (coord.), Estudios de historia moderna, 2, Valencia, Universidad, pp. 573-601.

FÀBREGA, Albert (2017), "La introducció i l'expansió de la patata i el blat de moro a Catalunya", Estudis d'Història Agrària, 28, pp. 13-46.

FAYA DíAz, María Ángeles (2007), "Economía y sociedad del occidente de Asturias y su relación con el Reino de Galicia”, en González Hernández, Helena et alii (ed.), VII Congreso Internacional Estudos Galegos, Sada, Ediciós do Castro, pp. 1031-1044.

FERnÁndeZ de Pinedo, Emiliano (1974), Crecimiento económico y transformaciones sociales del País Vasco (1100-1850), Madrid, Siglo XXI.

FERnÁndez Prieto, Lourenzo (ed.) (2000), Terra e progreso. Historia agraria da Galicia contemporánea, Vigo, Xerais.

Ferreiro Pérez, Rosa (1981), La Alta Limia en los siglos XVII-XVIII. Muestreo parroquial. Tesina de licenciatura, Santiago.

Galli, Marika (2016), La conquête alimentaire du Nouveau Monde. Pratiques et représentations franco-italiennes des nouveaux produits du XVIe au XVIII siècle, Paris, L'Harmattan.

GARcía GARCía, Aitor (2013), "Las actividades económicas en la montaña oriental leonesa durante la Edad Moderna", Estudios Humanísticos. Historia, 12, pp. 369-380. https://doi.org/10.18002/ehh.v0i12.973 
GARcía Ruíz, José Luis (1991), “Breve Historia de la patata (1845-1990)”, en López Linage, Javier (ed.), De papa a patata. La difusión española del tubérculo andino, Madrid, Lunwerg editores, pp. 133-168.

GARcía SANZ, Ángel (1994), "La ganadería española entre 1750 y 1865: los efectos de la reforma agraria liberal”, Agricultura y Sociedad, 72, pp. 81-119.

Garrabou Segura, Ramón, Pujol Andreu, Josep (1987), “El canvi agrari a la Catalunya del segle XIX", Recerques, 19, pp. 35-83.

Georgelin, Jean (1978), Venise au siècle des Lumières, Paris, Mouton.

Gil Rey, José María (1839), "Los gallegos", Semanario Pintoresco Español, pp. 345-347.

GonZÁLEZ ABELlÁs, Isaac César (1999), “Aproximación a las tendencias demográficas del valle de Monterrei durante el Antiguo Régimen: finales siglo XV-1900”, Cuadernos Feijonianos de Historia Moderna, I, pp. 11-50.

Hilbom, Ellen, Svensson, Patrick (eds). (2013), Agricultural Transformation in a Global History Perspective, London-New York, Routledge.

Hoyo, Jerónimo del (2016), Memorias del Arzobispado de Santiago, Reproducción Facsimilar, Santiago, Consorcio/Universidad.

Labrada, Lucas (1971), Descripción económica del Reino de Galicia, edic. de Río Barja, Francisco, Vigo, Galaxia.

Lains, Pedro, Pinilla, Vicente (eds.) (2009), Agriculture and Economic Development in Europe Since 1870, London-New York, Routledge.

LANZA GARCíA, Ramón (1991), La población y el crecimiento económico de Cantabria en el Antiguo Régimen, Madrid, Universidad Cantabria.

LANZA GARCÍA, Ramón (2001), "El crecimiento de la ganadería de Cantabria entre los siglos XVI y XIX: una temprana especialización regional”, Historia Agraria, 23, pp. 79-118.

LEVI, Giovanni (2014), "The diffusion of Maize in Italy: From Resistance to the Peasants' Defeat", en Aram, Bethany; Yun Casalilla, Bartolomé (eds.), Global Goods and the Spanish Empire, 1492-1824. Circulation, Resistance and Diversity, New York, Palgrave Macmillan, pp. 100-115. https://doi.org/10.1057/9781137324054_6

Lobo CABrera, Manuel (2008), El comercio canario europeo bajo Felipe II, Gran Canaria, Idea.

López Álvarez, María José et alii (1996), “Aproximación á dinámica evolutiva da poboación ourensá durante o Antigo Réxime”, Historia Nova, IV, pp. 91-110.

Madeline, Philippe, Moriceau, Jean-Marc (eds.) (2006), Acteurs et espaces de l'élevage (XVIIe-XXIe siècle). Évolution, structuration, spécialisation, Rennes, Association d'Histoire des Sociétés Rurales. 
Madoz, Pascual (1845-1850), Diccionario Geográfico-Estadístico-Histórico de España y sus posesiones de Ultramar, Madrid.

Melón, Miguel Ángel (1989), Extremadura en el Antiguo Régimen. Economía y sociedad en tierras de Cáceres. 1700-1810, Mérida, Regional de Extremadura.

MeIJIDE PARDo, Antonio (1984), Testimonios Históricos sobre la antigüedad del cultivo de la patata en Galicia, Sada, Gráficas do Castro.

MEYER, Jean (1980), "L'agriculture Bretonne au XVIII siècle”, en Actes du Ier. Colloque franco-irlandais d'Histoire économique et social, Dublin-París, pp. 21-35.

Miñano, Sebastián (1826-1829), Diccionario Geográfico-Estadístico de España y Portugal, Madrid, Imprenta Pierart-Peralta.

Mokyr, Joel (1981), “Irish History with the Potato”, Irish Economic and Social History, 8, pp. 8-29. https://doi.org/10.1177/033248938100800102

MOLINIER, Alain (1980), «En Vivarais au XVIIIe siècle: une croissance démographique sans révolution agricole», Annales du Midi: revue archéologique, historique et philologique de la France méridionale, T. 92, 148, pp. 301-316. https://doi. org/10.3406/anami.1980.1922

Morineau, Michel (1970), «La pomme de terre au XVIIIe siècle», Annales ESC, 25e Année, 6, pp. 1767-1785. https://doi.org/10.3406/ahess.1970.422316

Olsson, Mats, Svensson, Patrick (eds). (2011), Growth and stagnation in European historical agriculture, Turnhout, Brepols.

Ó GRÁDA, Cormac (1993), "Salud, trabajo y nutrición: Irlanda antes de la hambruna", Revista de Historia Económica-Journal of Iberian and Latin American Economic History, 11, 3, pp. 475-502. https://doi.org/10.1017/S0212610900004146

Ó GRÁDA, Cormac (2015), “Famine in Ireland, 1300-1900”, Working Papers, UCD Centre for Economic Research, 15/13, Dublin, School of Economics, University College, pp. 1-35.

Overton, Mark (1996), Agricultural Revolution in England: The Transformation of the Agrarian Economy 1500-1850, Cambridge, University Press.

Palanca CAÑón, José David (2011), Introducción y generalización del cultivo y consumo alimentario y médico de la patata en el País Vasco: 1760-1860, UPV/ EHU, Tesis doctoral.

PANJEK, Giovanni (1976), "In margine alla storia dell'alimentazione: Un dibattito sttecentesco sull'introduzione della patata nel Veneto", en AA.VV., Raccolta di scritti per il cinquentesimo aniversario, 1929-1974, Trieste, Università degli Studi, pp. 537-587.

PÉrez Álvarez, María José (1996), La montaña noroccidental leonesa en la Edad Moderna, León, Universidad. 
PÉrez Álvarez, María José (2004), “La cabaña ganadera en León: estructura interna, limitaciones y proceso evolutivo (siglos XVIII-XIX)", en Aranda Pérez, Francisco José (eds.), El mundo rural en la España Moderna, Cuenca, Universidad Castilla-La Mancha, pp. 789-807.

PÉrez GarcíA, José Manuel (1979), Un modelo de sociedad rural de Antiguo Régimen en la Galicia costera: la Península del Salnés, Santiago, Universidad.

PÉrez García, José Manuel (1981), “Aproximación al estudio de la penetración del maíz en Galicia”, en Eiras Roel, Antonio et alii, La historia social en sus fuentes de protocolos, Santiago, Universidad, pp. 117-159.

PÉrez García, José Manuel (1992), «Le mais dans le Nord-Ouest de la péninsule ibérique durant l'ancien régime», en Plantes et cultures nouvelles en Europe occidentale, au Moyen Age et à l'époque moderne, Flaran, 12, Auch, Comité Départemental du Tourisme du Gers, pp. 81-102.

PÉrez GarcíA, José Manuel (2004), "Entre regar y no regar: la intensa disputa por unos recursos hídricos colectivos escasos en la Galicia Meridional (1600-1850)”, en Aranda, José (eds.), El mundo rural en la España Moderna, Cuenca, Universidad Castilla-La Mancha, pp. 555-572.

PÉrez GARCÍA, José Manuel (2006), “De la escasez a la precoz saturación: el desarrollo demográfico de la comarca del Bajo Miño (1550-1850)", Cuadernos Feijonianos de Historia Moderna, III, pp. 53-102.

PÉrez GARCÍA, José Manuel (2007), "La España agraria septentrional durante el Antiguo Régimen (1500-1850)”, Studia Histórica. Historia Moderna, 29, pp. 83-129.

PÉrEz SAMPER, María de los Ángeles (2009), “La alimentación cotidiana en la España del siglo XVIII”, en García Hurtado, Manuel-Reyes (ed.), La vida cotidiana en la España del siglo XVIII, Madrid, Sílex, pp. 11-55.

PÉrez SAMPer, María de los Ángeles (2013), "Comer o no comer, esa es la cuestión: la alimentación en tiempos de guerra en la Cataluña de 1713 y 1813 ”, en Dantí, Jaume et alii (coords.), Catalunya, entre la guerra y la pau, 1713-1813, Barcelona, Universidad.

PÉrez SAMPER, María de los Ángeles (2014), "The Early Modern Fod Revolution: A Perspective from the Iberian Atlantic", en Aram, Bethany; Yun Casalilla, Bartolomé (eds.), Global Goods and the Spanish Empire, 1492-1824. Circulation, Resistance and Diversity, New York, Palgrave Macmillan, pp. 17-37.

PiQueras HaBA, Juan (1992), "La difusión de la patata en España (1750-1850): el papel de las sociedades económicas y del clero rural”, Ería: Revista cuatrimestral de geografia, 27, pp. 80-89.

PiQueras HabA, Juan (1992a), Sociedades Económicas y fomento de la agricultura en España, 1765-1850, Valencia, Generalitat. 
Poitrineau, Abel (1962), «L'alimentation populaire en Auvergne au XVIIIe siècle», Annales. ESC, 17e année, 2, pp. 323-331.

PoITRINEAU, Abel (1979), La vie rurale en Basse-Auvergne au XVIIIe siècle, Marseille, Laffitte reprints.

Presedo Garazo, Antonio (1997), "Estructura, productividade e rendementos agrícolas da explotación campesiña na Galicia interior: o partido xudicial de Arzúa en 1750-1860", Semata, 9, p. 245-277.

Presedo Garazo, Antonio (2009), “A contribución das plantas agrícolas de orixe americana á economía galega nos séculos XVII-XIX: o millo e a pataca”, en Anderson, JoDee, et alii (eds.), América, Américas. Perspectivas sobre el Nuevo Mundo y su relación con Europa, Lugo, AXAC, pp. 127-146.

Quiroga BARro, Gabriel (1988), Evolución dunha estructura agraria na Galicia interior: A Terra de Viana do Bolo, 1600-1820, Boletín Avriense. Anexo 15, Ourense, Museo Arqueolóxico.

Rey CAStelao, Ofelia (2012), "La lucha por el agua en el país de la lluvia (Galicia, XVI-XIX)", Vínculos de História, 1, pp. 45-72.

Riera Climent, Luis, Riera Palmeiro, Juan (2007), “Los alimentos americanos en los Extractos de la Bascongada (1768-1793): El Maíz y la Patata”, ILUIL, 30, pp. 319-332.

Rodríguez Ferreiro, Hilario (1995), “Economía y población rural en la Galicia atlántica: El Morrazo en los siglos XVII y XVIII”, Minius, IV, pp. 89-98.

Rodríguez Ferreiro, Hilario (2003), A Xurisdicción do Morrazo, XVII-XVIII, Pontevedra, Diputación.

Rodríguez Galdo, María Xosé (1991), "Introducción y difusión del cultivo de la patata en España (XVI-XVIII)”, en López Linage, Javier (ed.), De papa a patata..., pp. 81-103.

Rodríguez Galdo, María Xosé, Dopico, Fausto (1980), "Novos cultivos e agricultura tradicional: a pataca en Galicia nos séculos XVIII e XIX”, Revista galega de Estudios Agrarios, 3, pp. 11-37.

Rodríguez FERnÁNDEZ, Delfina (1999), A terra e as xentes. Nacer, vivir e morrer na comarca de Celanova ó longo da Idade Moderna, A Coruña, Vía Láctea.

RoDRíGUEZ FERNÁNDEZ, Delfina (2006), “Dinámica evolutiva de la cultura agraria celanovesa durante el Antiguo Régimen”, Cuadernos Feijonianos Historia Moderna, III, pp. 105-130.

RozIER, François (1797), Diccionario Universal de Agricultura ..., traducido por Juan Álvarez Guerra, Madrid, Imprenta Real, vol. 1. 
Rubio PÉRez, Laureano (1987), La Bañeza y su tierra, 1650-1850. Un modelo de sociedad rural leonesa, León, Universidad.

Rubio PÉrez, Laureano (1997), “Agua, regadío y conflicto social en la provincia de León durante la Edad Moderna", Estudios humanísticos, 19, pp. 87-114.

SAAVEDRA, Pegerto (1979), Economía rural antigua en la montaña lucense. El concejo de Burón, Santiago, Universidad.

SaAvedra, Pegerto (1985), Economía, Politica y Sociedad en Galicia. La Provincia de Mondoñedo, 1480-1830, Madrid, Xunta Galicia.

SAAVEDRA, Pegerto (1992), "La dinámica de la petita explotació pagesa a la Galicia de l'antic régim”, Recerques. Història, economia i cultura, 25, pp. 105-124.

SAAVEDRA, Pegerto (1993), "Las grandes tendencias comarcales en la evolución de la población gallega (de comienzos del XVII a mediados del XIX)”, Revista Stvdia Histórica, XI, pp. 11-59.

SaAvedra, Pegerto (1994), La vida cotidiana en la Galicia del Antiguo Régimen, Barcelona, Crítica.

SAAVEDRA, Pegerto (1999), «Petite exploitation et changement agricole à l'interieur d'un vieux complexe agraire. Les campagnes de la Galice entre 1550 et 1850 », Histoire \& Sociétés Rurales, 12, 2e semestre, pp. 63-108.

SAAVEDRA, Pegerto (2008), «Les prairies dans les systémes agraires de l'Ibérie humide», Flaran, XXVIII, pp. 169-192.

SAAVEDRA, Pegerto (2008b), "La influencia de la especialización pecuaria en el paisaje agrario de la España cantábrica y noratlántica (siglos XVIII-XIX)”, en Franch Benavent, Rafael y Benítez Sánchez-Blanco, Ricardo (coord.), Estudios de historia moderna, 2, Valencia, Universidad, pp. 747-766.

SAAVEDRA, Pegerto (2009), "El agua en el sistema agropecuario de Galicia”, en Marcos Martín, Alberto (coord.), Agua y sociedad en la época moderna, Valladolid, Universidad/Instituto Universidad de Historia Simancas, pp. 49-72.

SAAVEDRA, Pegerto (2010), “Trayectoria de las rentas monásticas y del sistema agrario de Galicia desde la segunda mitad del XVI a 1835", Revista Portuguesa de História, XLI, pp. 105-156. https://doi.org/10.14195/0870-4147_41_5

SAAVEDRA, Pegerto (2015), "El paisaje desde 1500 a 1850: la creación por los campesinos de un "viejo complejo agrario", en Pereira Menaut, Gerardo y Portela Silva, Ermelindo (coords.), El territorio en la historia de Galicia: organización y control, siglos I-XXI, Santiago, USC, pp. 153-250.

Salaman, Redcliffe N. (1991), Historia e influencia social de la patata, Madrid, Ministerio Trabajo. 
SÁnchez, Pedro Antonio (1973), La economía gallega en los escritos de..., edic. de Xosé Manuel Beiras, Vigo, Galaxia.

SÁNCHEZ Rodríguez, Ana (2003), "La agricultura gallega en la crisis del Antiguo Régimen: tentativas modernizadoras", Obradoiro de Historia Moderna, 12, pp. 223-246. https://doi.org/10.15304/ohm.12.620

SÁnchez Romero, Gregorio (1990), "Introducción de los cultivos americanos en el noroeste murciano. El caso de Caravaca en el siglo XVIII", Anales de Historia Contemporánea, 8, pp. 259-265.

Sandoval Verea, Francisco Manuel (1999), A xurisdicción de Folgoso a finais do Antigo Réxime, Tesina de Licenciatura, Santiago.

Smith, Adam (1794), Investigación de la naturaleza y causas de la Riqueza de las Naciones, vol. 1, Valladolid, en la oficina de la viuda e hijos de Santander.

Sobrado Correa, Hortensio (2001), Las tierras de Lugo en la Edad Moderna. Economía campesina, familia y herencia, 1550-1860, A Coruña, Fundación Pedro Barrié de la Maza.

Sobrado CorreA, Hortensio (2010), "Transformaciones del paisaje agrario gallego en la Edad Moderna”, Spanish Journal of Rural Development, 1, № 3, pp. 71-84.

Sobral Neto, Margarida (1994), "Introduçâo e expansâo de cultura da batata na regiâo de Coimbra (secs. XVII-XIX)", Revista portuguesa de História, XXIX, pp. 55-83.

Sobral Neto, Margarida (1997), Terra e conflito. Regiâo de Coimbra, 1700-1834, Viséu, Palimage Editores.

ToriJa IsasA, Esperanza (2009), "La alimentación en la época de la Guerra de la Independencia", Anales de la Real Academia Nacional de Farmacia, 75, pp. 613-638.

VANDENBROEKE, Chris (1975), Agriculture et alimentation. L'agriculture et alimentation dans les Pays-Bas autrichiens. Contribution a l'histoire économique et sociales à la fin de l'Ancien Régime, Gante-Lovaina.

VIEGAS GuERrEIRO, Manuel (1987), “A cultura da batata, súa introduçâo na Europa. O caso de Portugal", Memórias da Academia das Ciencias de Lisboa, Letras, XXVI, Lisboa.

Villares PaZ, Ramón (1973), Los Inventarios post-mortem como fuente para el estudio de la Historia rural y la economía agraria. Comarca de Santiago, 1675-1715, Santiago, Tesina de Licenciatura.

Villares PaZ, Ramón (1982), La propiedad de la tierra en Galicia, 1500-1836, Madrid, Siglo XXI. 
Yun CASAlilla, Bartolomé (2014), "The Spanish Empire. Globalization, and Cross-Cultural Consumption in a World Contex, c.1400-c.1750", en Aram, Bethany; Yun Casalilla, Bartolomé (eds.), Global Goods and the Spanish Empire, 1492-1824. Circulation, Resistance and Diversity, New York, Palgrave Macmillan, pp. 277-306. 